\title{
Performance Evaluation of a High Bandwidth Liquid Fuel Modulation Valve for Active Combustion Control
}

Joseph R. Saus, John C. DeLaat, Clarence T. Chang, and Daniel R. Vrnak Glenn Research Center, Cleveland, Ohio 


\section{NASA STI Program . . . in Profile}

Since its founding, NASA has been dedicated to the advancement of aeronautics and space science. The NASA Scientific and Technical Information (STI) program plays a key part in helping NASA maintain this important role.

The NASA STI Program operates under the auspices of the Agency Chief Information Officer. It collects, organizes, provides for archiving, and disseminates NASA's STI. The NASA STI program provides access to the NASA Aeronautics and Space Database and its public interface, the NASA Technical Reports Server, thus providing one of the largest collections of aeronautical and space science STI in the world. Results are published in both non-NASA channels and by NASA in the NASA STI Report Series, which includes the following report types:

- TECHNICAL PUBLICATION. Reports of completed research or a major significant phase of research that present the results of NASA programs and include extensive data or theoretical analysis. Includes compilations of significant scientific and technical data and information deemed to be of continuing reference value. NASA counterpart of peer-reviewed formal professional papers but has less stringent limitations on manuscript length and extent of graphic presentations.

- TECHNICAL MEMORANDUM. Scientific and technical findings that are preliminary or of specialized interest, e.g., quick release reports, working papers, and bibliographies that contain minimal annotation. Does not contain extensive analysis.

- CONTRACTOR REPORT. Scientific and technical findings by NASA-sponsored contractors and grantees.
- CONFERENCE PUBLICATION. Collected papers from scientific and technical conferences, symposia, seminars, or other meetings sponsored or cosponsored by NASA.

- SPECIAL PUBLICATION. Scientific, technical, or historical information from NASA programs, projects, and missions, often concerned with subjects having substantial public interest.

- TECHNICAL TRANSLATION. Englishlanguage translations of foreign scientific and technical material pertinent to NASA's mission.

Specialized services also include creating custom thesauri, building customized databases, organizing and publishing research results.

For more information about the NASA STI program, see the following:

- Access the NASA STI program home page at http://www.sti.nasa.gov

- E-mail your question to help@sti.nasa.gov

- Fax your question to the NASA STI Information Desk at 443-757-5803

- Phone the NASA STI Information Desk at 443-757-5802

- Write to: STI Information Desk NASA Center for AeroSpace Information 7115 Standard Drive Hanover, MD 21076-1320 


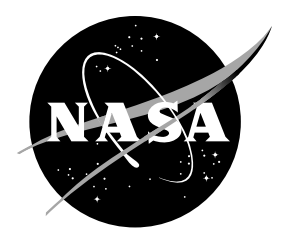

\section{Performance Evaluation of a High Bandwidth Liquid Fuel Modulation Valve for Active Combustion Control}

Joseph R. Saus, John C. DeLaat, Clarence T. Chang, and Daniel R. Vrnak Glenn Research Center, Cleveland, Ohio

Prepared for the

50th Aerospace Sciences Meeting

sponsored by the American Institute of Aeronautics and Astronautics

Nashville, Tennessee, January 9-12, 2012

National Aeronautics and

Space Administration

Glenn Research Center

Cleveland, Ohio 44135 


\section{Acknowledgments}

The authors wish to acknowledge Dr. Daniel Paxson for his consultation on issues surrounding the optimization of the GTV for off-nominal design operation and for his modeling efforts that supported our active combustion control research. This work was sponsored by the Fundamental Aeronautics Program and the Environmentally Responsible Aviation Project at the NASA Glenn Research Center.

Trade names and trademarks are used in this report for identification only. Their usage does not constitute an official endorsement, either expressed or implied, by the National Aeronautics and Space Administration.

Level of Review: This material has been technically reviewed by technical management.

Available from

NASA Center for Aerospace Information 7115 Standard Drive

Hanover, MD 21076-1320
National Technical Information Service 5301 Shawnee Road Alexandria, VA 22312

Available electronically at http://www.sti.nasa.gov 


\title{
Performance Evaluation of a High Bandwidth Liquid Fuel Modulation Valve for Active Combustion Control
}

\author{
Joseph R. Saus, John C. DeLaat, Clarence T. Chang, and Daniel R. Vrnak \\ National Aeronautics and Space Administration \\ Glenn Research Center \\ Cleveland, Ohio 44135
}

\begin{abstract}
At the NASA Glenn Research Center, a characterization rig was designed and constructed for the purpose of evaluating high bandwidth liquid fuel modulation devices to determine their suitability for active combustion control research. Incorporated into the rig's design are features that approximate conditions similar to those that would be encountered by a candidate device if it were installed on an actual combustion research rig. The characterized dynamic performance measures obtained through testing in the rig are planned to be accurate indicators of expected performance in an actual combustion testing environment. To evaluate how well the characterization rig predicts fuel modulator dynamic performance, characterization rig data was compared with performance data for a fuel modulator candidate when the candidate was in operation during combustion testing. Specifically, the nominal and off-nominal performance data for a magnetostrictive-actuated proportional fuel modulation valve is described. Valve performance data were collected with the characterization rig configured to emulate two different combustion rig fuel feed systems. Fuel mass flows and pressures, fuel feed line lengths, and fuel injector orifice size was approximated in the characterization rig. Valve performance data were also collected with the valve modulating the fuel into the two combustor rigs. Comparison of the predicted and actual valve performance data show that when the valve is operated near its design condition the characterization rig can appropriately predict the installed performance of the valve. Improvements to the characterization rig and accompanying modeling activities are underway to more accurately predict performance, especially for the devices under development to modulate fuel into the much smaller fuel injectors anticipated in future lean-burning low-emissions aircraft engine combustors.
\end{abstract}

\section{Nomenclature}

$\mathrm{AC}_{\mathrm{d}} \quad$ cross sectional area corrected by discharge coefficient

$\mathrm{FN}_{\mathrm{i}} \quad$ flow number of the fuel injection orifice

$\mathrm{FN}_{\mathrm{m}} \quad$ flow number of the fuel modulator discharge orifice

$\dot{m}_{f} \quad$ mass flow rate

DP32 differential pressure across fuel modulator (characterization rig)

DP43 differential pressure across injection orifice (characterization rig)

P1 static pressure immediately upstream of accumulator (characterization rig)

P2 static pressure immediately upstream of fuel modulator (characterization rig)

P3a static pressure at fuel modulator discharge (characterization rig)

P3b static pressure upstream of injection orifice (characterization rig)

P4 static pressure downstream of the fuel injector in either the simulated or actual combustor

P4dynup static pressure immediately downstream of injector (combustion testing)

P4dyndn static pressure downstream of P4dynup (combustion testing)

Pvupstr static pressure upstream of fuel modulator (combustion testing)

Pvdnstr static pressure downstream of fuel modulator (combustion testing) 


$\begin{array}{ll}\text { SC } & \text { simulated combustor (characterization rig) } \\ \text { TFE } & \text { transfer function estimate } \\ \text { TS } & \text { test section (characterization rig) }\end{array}$

\section{Introduction}

In response to increasingly strict limitations on emission output levels for both land-based and aircraft gas turbine engines, combustion research has focused on leaner-burning combustion concepts. However, these leaner-burning concepts have shown an increased susceptibility to combustion instabilities (Refs. 1 to 5). These instabilities can cause combustor pressure oscillations which left unchecked, lead to increased vibration levels and potentially premature mechanical failure. One of the mechanisms that have been identified as contributing to these instabilities is the coupling of the combustion heat release with the inherent combustor geometry acoustics (thermo-acoustic instabilities). Ideally, passive techniques would be the most attractive solution to solve these problems because they minimize weight and component count. However, given the range of conditions over the complete mission cycle of the engine, a passive technique may not be fully successful. For this reason, it is prudent to also investigate techniques for active control (Refs. 5 to 17).

Active Combustion Instability Control (ACIC) addresses the instability mechanism previously mentioned. The basic approach is to modulate fuel into the combustor so as to decouple the combustion heat release process from geometry-induced acoustic frequencies that produce instabilities. If performed correctly (i.e., supplying appropriate magnitude and phase in the modulated fuel output), the result of the control action attenuates the amplitude of the instability.

The success of providing active control, then, hinges largely upon having a fuel actuator with adequate bandwidth and modulation strength to cover the frequency range over which instabilities have been observed. In the body of research to date, combustion instabilities in gas turbine engines have generally been observed in the 100 to $1000 \mathrm{~Hz}$ range (military engines have encountered some even higher). Unfortunately, actuators with this type of bandwidth are not available as off-the-shelf manufactured items. Therefore, it has become necessary to develop custom fuel actuators which satisfy these requirements.

In order to ensure that the performance of a given candidate fuel modulator is suitable for use in an active control application; it becomes necessary to perform dynamic characterization testing. It is for this reason that a characterization test rig was designed and developed at the NASA Glenn Research Center. The goal of the rig's design was to incorporate features that would permit accurate simulation of conditions similar to what a candidate fuel modulation valve would experience if it were connected to a research combustion rig (sans flame and temperature) (Ref. 18).

In order to evaluate the ability of the characterization rig in predicting the fuel modulator's performance, comparisons are made between the predicted characterized performance of a modulation candidate with performance measured when operating in the more realistic environment of an experimental combustion rig. Agreement between these two sets of data provides a good measure of validation. NASA Glenn has conducted an evaluation on a single fuel modulation candidate that has been used for in-house ACIC research with two distinct combustion rig platforms. It is the intent of this paper to report on those evaluations.

This paper begins with a description of the fuel modulator characterization rig. The fuel modulator test candidate is then described including the initial specifications that were used to arrive at its nominal design point and the test conditions for the characterization and combustion testing. Following this, the paper describes the two combustion rigs from which data are used to validate the characterization rig. Next, the data collected from the characterization rig is compared with performance data obtained from the combustion rigs. In closing, conclusions are drawn on these comparisons and future research directions are discussed. 


\section{The Characterization Rig}

To determine whether or not a high bandwidth fuel modulator is a suitable candidate for ACIC research, a means of testing it is required. Conceivably this can be accomplished in situ when connected to a combustion rig, but it is not practical to do this for various reasons including: 1) expensive operational costs; 2) the possibility of damaging equipment (more cost and loss of research time); and 3) loss of available time to conduct actual combustion research. In response to these reasons, NASA GRC designed and developed a characterization rig capable of evaluating high bandwidth fuel modulators. Shown schematically in Figure 1, the design incorporates features intended to approximate conditions similar to those that would be experienced by the test candidate if connected to a combustion rig. As seen, the schematic defines the rig as three distinct subsystems. These subsystems are the Fluid Supply System, the Test Section (TS), and the Ancillary System (ancillary to the Test Section). A detailed description of the rig is given in Reference 18. For this paper it is sufficient to focus on the rig's test section which is shown isolated from the rig schematic in Figure 2.

The TS positions the test article between an accumulator and another pressure vessel referred to as the Simulated Combustor (SC). The working fluid entering the TS is city water supplied under pressure by a positive displacement piston pump. The supply is both regulated and pre-conditioned. Maximum working pressure is 600 psig. The accumulator receives this pre-conditioned flow and provides two main functions: 1) it provides the test candidate with a constant pressure supply of working fluid; and 2) it acts as a filter for damping pressure fluctuations introduced by the pump.

The functionality of the SC is also twofold. First, it simulates the fuel injector. A set of pipe nipples, $1 \frac{1}{2}$ in. length by $1 / 8$ in. inside diameter, each contain a precision orifice insert to allow the selection of a known orifice diameter. Given this potential for interchangeability, it is possible to select an orifice diameter that would closely approximate the cross sectional area of a known fuel injector.

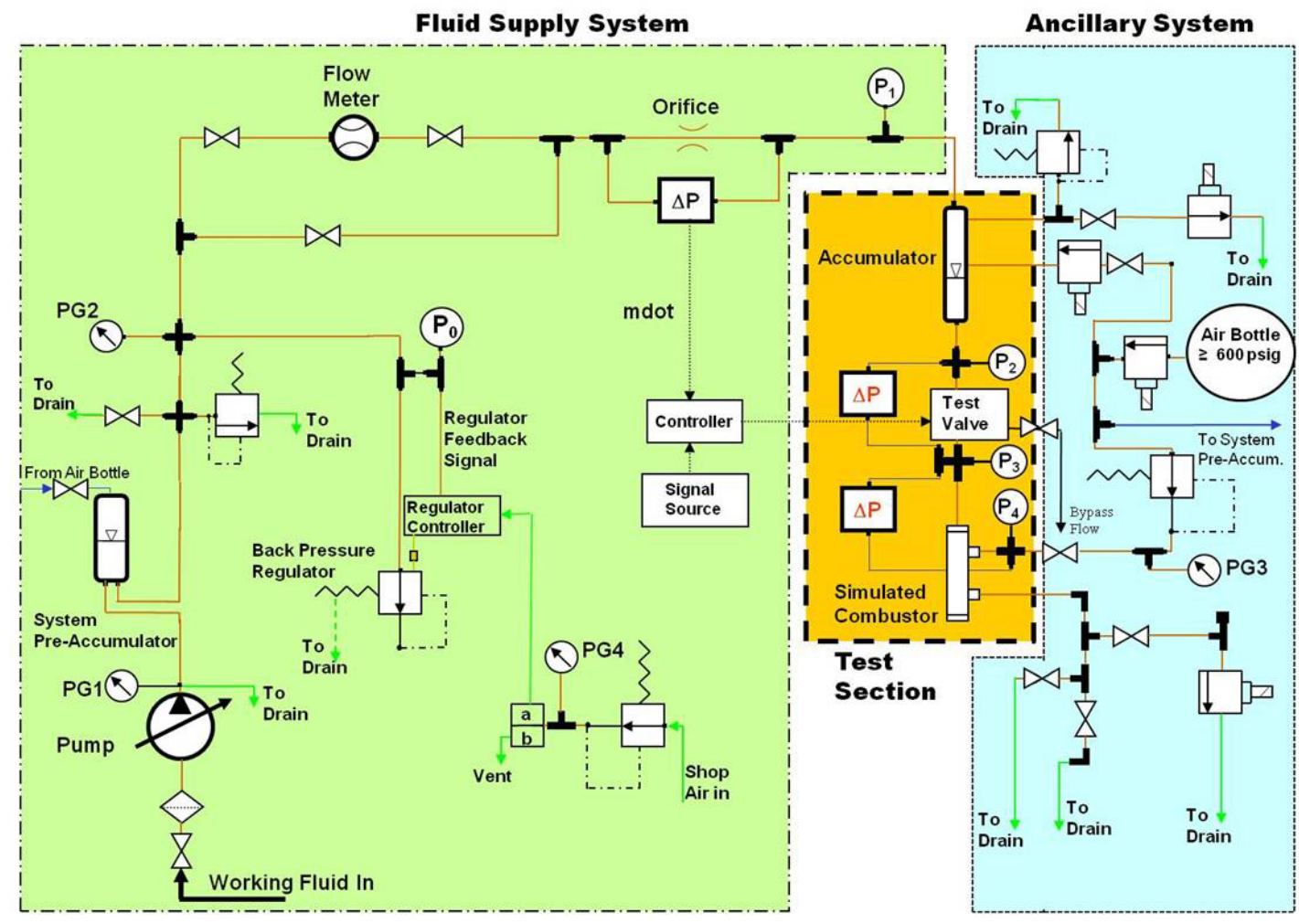

Figure 1.-Schematic of the NASA GRC high bandwidth valve characterization rig. 


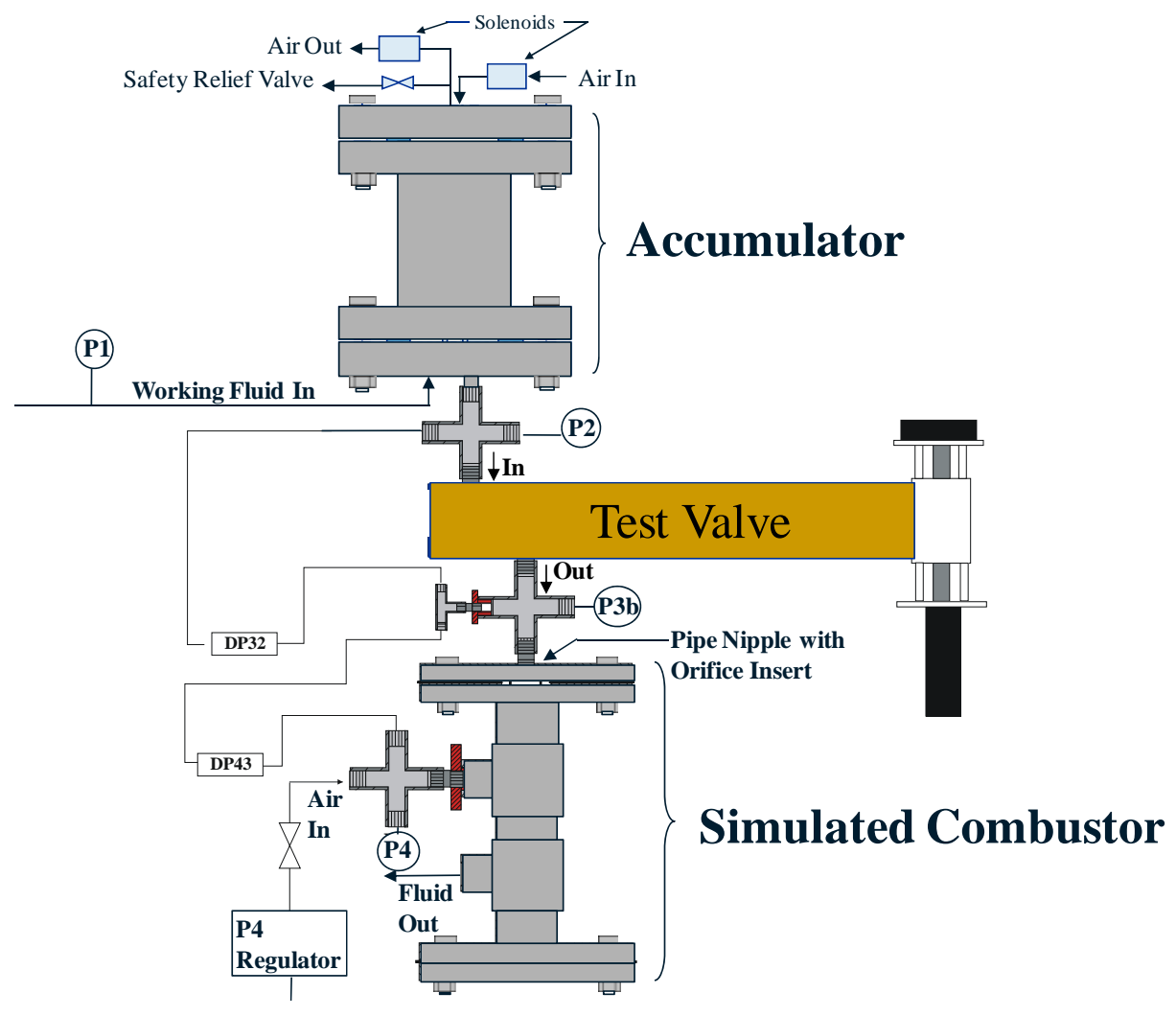

Figure 2.-The characterization rig test section. Depicted is the "short configuration". Introducing a length of tubing between the test valve's discharge and the pipe cross housing pressure transducer P3b creates the "long configuration". Other changeable items in the test section include the test valve itself and the pipe nipple with the orifice insert.

On the downstream side of this simulated injector, the SC serves its second function which is to provide a pressurized, gaseous environment similar to what would be encountered in a combustion rig. Regulated compressed air is supplied to the SC by the Ancillary System. When the modulator's discharge enters the pressurized environment, the fluid accumulates on the bottom of the SC and eventually evacuates through the Ancillary System to a drain. The fluid is not recirculated and reused in order to avoid air entrainment that can increase the compressibility of the fluid and impact a test candidate's performance.

Flow measurements are taken upstream of the TS. Within the TS both absolute and differential pressure measurements are collected. Specifically, the absolute, high-frequency pressure measurements are collected upstream and downstream of the test candidate (P2 and P3b, respectively) and also downstream of the simulated injection orifice (P4); the differential pressures measured are those across the test candidate (DP32) and across the injection orifice (DP43). All data are recorded to a dSpace highspeed data acquisition system.

The operational procedures in the characterization rig are intended to simulate tests and procedures performed when the fuel modulator is operating in a combustion rig environment. These procedures typically begin with the establishment of a flow condition consisting of the desired mass flow, inlet pressure, and exit pressure (in the combustor rig, the operating temperature would also be set). Once the appropriate conditions are established, another series of tests are performed to measure the frequency response of the test article to determine its authority over the bandwidth of interest. For the first of these tests, a signal generator is used to command the test article with a fixed amplitude sinusoidal input to 
cause modulation at discrete frequencies within a user-defined range. At each frequency the average mass flow and high-frequency pressure measurements are recorded. The frequencies in the range are typically commanded in order from smallest to largest and then again from largest to smallest. The reverse direction traverse is meant to be a means of getting repeat data as well as to check for hysteresis. Once the data for these perturbation tests has been collected, a second test consisting of a logarithmic sinusoidal frequency sweeping, is performed over the same frequency range used for perturbation testing. At the conclusion of the frequency sweep tests the rig can be reset for a different flow condition or it can be shutdown to permit a physical configuration change.

Characterization rig "baseline" data for the candidate fuel modulator is the collection of pressure measurements for the plumbing configuration depicted in Figure 2. This is referred to as the "short configuration" since all fluid pathways between the fuel modulator's inlet and the entrance of the simulated injection orifice were made as short as possible. By doing this it is assumed that the best potential performance for the fuel modulator candidate can be measured due to minimum line losses. The "short configuration" is also shown schematically in Figure 3(a).

In a combustion rig, the fuel modulator is connected externally. The transport of modulated fuel pulses from the connection point to the actual fuel injector occurs through a length of tubing internal to the combustion rig. This is shown schematically in Figure 3(b). During combustor testing, the pressures upstream and downstream of the valve are labeled as Pvupstr and Pvdnstr in order to avoid confusion with the P2 and P3 notation normally associated with engine stations. To simulate the additional feed line length encountered during combustor testing, the characterization rig hardware is changed from the baseline "short configuration" by adding a length of tubing between the candidate's discharge and the SC. This is referred to as the "long configuration" and is shown schematically in Figure 3(c).

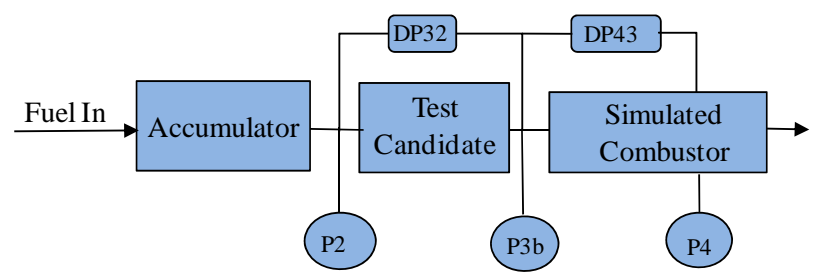

a) Characterization Rig “Short Configuration"

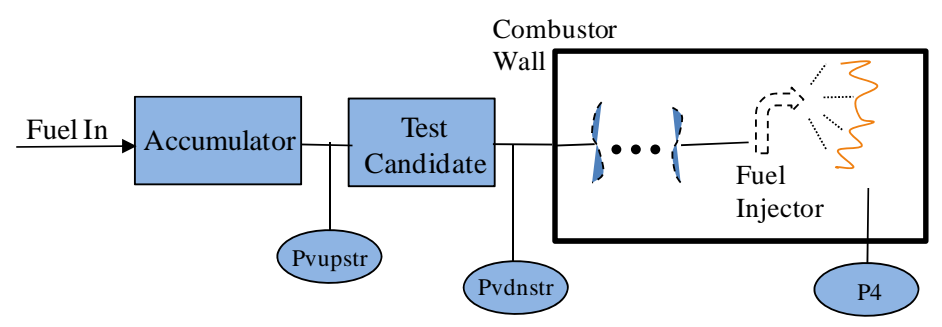

b) Combustion Rig Testing

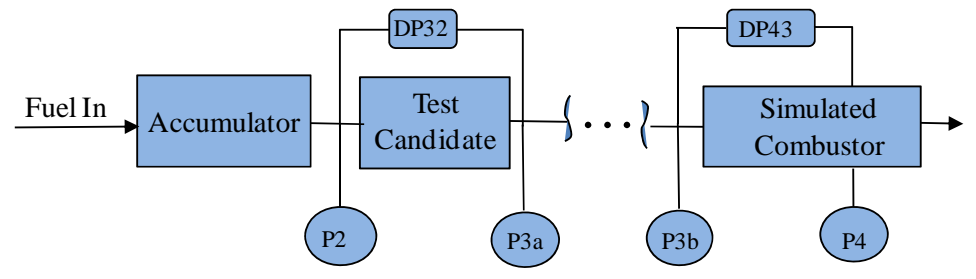

c) Characterization Rig “Long Configuration”

Figure 3.-Schematic summaries of instrumentation for the characterization rig and for generic combustion testing. 
TABLE I.-PRESSURE MEASUREMENT PARALLELS FOR FIGURE 3 TESTING CONFIGURATIONS

\begin{tabular}{|l|c|c|c|c|}
\hline $\begin{array}{c}\text { Equivalent instrumentation between configurations } \\
\text { in Figure 3 }\end{array}$ & $\begin{array}{c}\text { Test valve } \\
\text { upstream } \\
\text { pressure }\end{array}$ & $\begin{array}{c}\text { Test valve } \\
\text { downstream } \\
\text { pressure }\end{array}$ & $\begin{array}{c}\text { Injector } \\
\text { upstream } \\
\text { pressure }\end{array}$ & $\begin{array}{c}\text { Injector } \\
\text { downstream } \\
\text { pressure }\end{array}$ \\
\hline Figure 3(a): Characterization rig short & P2 & P3b & P3b & P4 \\
\hline Figure 3(b): Combustion rig & Pvupstr & Pvdnstr & N/A & P4 \\
\hline Figure 3(c): Characterization rig long & P2 & P3a & P3b & P4 \\
\hline
\end{tabular}

In this configuration, an additional high-frequency pressure transducer is introduced, P3a, that measures the candidate's discharge pressure at the upstream end of the added tube length. Transducer, P3b, continues to measure the fuel injector inlet pressure, but it does so at the downstream end of the added tube length. For this "long configuration”, differences in performance are expected due to line losses and resonance shift. The resulting pressure measurements provide more realistic predictions of expected performance for when the fuel modulator is mated with an actual combustor rig. Table I summarizes the measurements made upstream and downstream of the fuel modulator as well as the measurements made upstream and downstream of the injector for the various configurations shown in Figure 3. A subset of these measurements will be compared in the Results section of this paper to evaluate similarities in performance between the characterization rig and the combustion rigs.

\section{The Candidate Test Article}

As stated earlier, liquid fuel modulators possessing appropriate bandwidth characteristics are critical to the successful implementation of ACIC. These devices are typically custom-made items. During NASA GRC's initial ACIC research, specifications for a fuel modulation device were developed based on the estimated flow modulation required. These specifications are shown in Table II. For that initial research the focus was on utilizing a combustion platform that was designed to replicate instabilities observed for a real prototype gas turbine engine. For that conventional rich-burn, single nozzle combustion platform, the fuel injector main fuel nozzle had a flow number of $110 \mathrm{lbm} \cdot \mathrm{hr}^{-1} \cdot \mathrm{psi}^{-0.5}$. Flow number (FN) for an orifice is defined as the ratio of the fuel mass flow rate [in units of (lbm/hr); equivalent to pounds per hour (pph)] to the square root of the pressure difference (in units of psi) across the orifice. Henceforth, when flow numbers are referred to in this paper, the units on flow number will not be stated, rather they will be assumed to have the units already shown. Flow number, as just defined, is primarily used in the fuel injector research realm. Linking it to a more accepted Fluid Mechanics convention, flow number is proportional to the corrected cross sectional area, $\mathrm{AC}_{\mathrm{d}}$. A datum for this relationship would be as follows: a flow number of 100 would be comparable to an $A_{d}$ of $5.9 \mathrm{E}-3$ in. ${ }^{2}$ $\left(3.8 \mathrm{E}-6 \mathrm{~m}^{2}\right)$.

At the time these specifications were defined, Georgia Institute of Technology had reported on a high bandwidth valve design that they had developed and validated (Ref. 19). NASA GRC examined the valve performance data and subsequently awarded Georgia Tech a contract to build a valve for NASA GRC's ACIC research. The fuel modulation test candidate being reported in this paper is the valve designed, fabricated, and assembled by Georgia Institute of Technology. This paper will refer to it as the Georgia Tech Valve (GTV). For proprietary reasons, a full disclosure of the GTV's construction cannot be made. In general terms, however, it can be said that it is of modular construction consisting of a high frequency actuation component and a proportional valve. The actuation component is a magneto-strictive stack that is mechanically coupled to the proportional valve such that when the stack is energized, it changes the proportional valve's orifice and thus produces changes in fuel pressure with resulting changes in fuel mass flow. A DC motor is connected to the remote end of the stack to cause the stack to translate. This allows a change in the mean proportional valve position and thus the mean flow rate. A signal generator is used to supply a sinusoidal signal to the magneto-strictive stack for generating the high frequency displacements. A proportional-integral controller, using a measurement of the mass flow rate as feedback, is used to generate commands for the motor that translates the stack as necessary to minimize the error between the mass flow rate measurement and a user-stipulated mean mass flow rate set point. 
TABLE II.-INITIAL DESIGN SPECIFICATIONS

FOR HIGH FREQUENCY VALVE

\begin{tabular}{|l|l|}
\hline Characteristic & Specification \\
\hline Maximum mean fuel flow rate & $500 \mathrm{lbm} / \mathrm{hr}$ \\
\hline Maximum inlet pressure & $600 \mathrm{psi}$ \\
\hline Maximum pressure drop & $300 \mathrm{psi}$ \\
\hline Modulation authority & $\pm 40 \%$ of the mean flow \\
\hline Minimum bandwidth & $600 \mathrm{~Hz}$ \\
\hline Working fluid & Liquid jet fuel \\
\hline
\end{tabular}

TABLE III.-DEFINED OPERATING CONDITIONS FOR THE CONVENTIONAL RICH-BURN COMBUSTION RIG

\begin{tabular}{|c|c|c|c|}
\hline $\begin{array}{c}\mathrm{FN}_{\mathrm{i}} \\
\left(\mathrm{pph}_{\mathrm{psi}}{ }^{-0.5}\right)\end{array}$ & $\begin{array}{c}\mathrm{FN}_{\mathrm{m}} \\
\left(\mathrm{pph}^{-0.5} \mathrm{pi}^{-0.5}\right)\end{array}$ & $\begin{array}{c}\dot{m}_{f} \\
(\mathrm{pph})\end{array}$ & $\begin{array}{c}\mathrm{P}_{4} \\
(\mathrm{psig})\end{array}$ \\
\hline 110 & 23 & 500 & 200 \\
\hline 110 & 23 & 375 & 200 \\
\hline 110 & 23 & 250 & 200 \\
\hline
\end{tabular}

TABLE IV.-DEFINED OPERATING CONDITIONS FOR THE LEAN-BURN ADVANCED COMBUSTOR PROTOTYPE

\begin{tabular}{|c|c|c|c|}
\hline $\begin{array}{c}\mathrm{FN}_{\mathrm{i}} \\
\left(\mathrm{pph} \cdot \mathrm{psi}^{-0.5}\right)\end{array}$ & $\begin{array}{c}\mathrm{FN}_{\mathrm{m}} \\
\left(\mathrm{pph}^{-0.5} \mathrm{ps}^{-0.5}\right.\end{array}$ & $\begin{array}{c}\dot{m}_{f} \\
(\mathrm{pph})\end{array}$ & $\begin{array}{c}\mathrm{P}_{4} \\
(\mathrm{psig})\end{array}$ \\
\hline 8 & 8 & 75 & 250 \\
\hline 8 & 8 & 50 & 151 \\
\hline 8 & 8 & 25 & 166 \\
\hline
\end{tabular}

The operating conditions that were defined for the single nozzle combustion rig (and which therefore influenced the GTV design and operation) are shown in Table III. As can be seen, a condition is typically defined by a mass flow rate, $\dot{m}_{f}$, and the pressure downstream of the fuel injector, P4. It is important to note that there are two flow orifices present in the fuel feed system: one associated with the fuel modulator and one associated with the fuel injector. This paper will explicitly label a flow number as $\mathrm{FN}_{\mathrm{m}}$ (flow number of the modulator orifice) or $\mathrm{FN}_{\mathrm{i}}$ (flow number of the injector). For the conditions shown in Table III, it should be noted that the flow number for the GTV's orifice was set for around 23 when operating with the injector having the flow number of 110.This was done so as to make the GTV the controlling influence in the flow circuit.

After the initial proof-of-concept of ACIC for a conventional rich-burn combustor, NASA GRC's research objectives turned to demonstration of ACIC for lean-burning combustors designed for very low emissions. An advanced lean-burning low-emissions combustor prototype was available for testing at NASA GRC that exhibited a combustion instability. For this combustion platform the main fuel injector had a flow number of approximately 30 and the pilot fuel injector had a flow number of approximately 8 . In making the switch to this new combustion platform, there was not a corresponding switch to a fuel modulation valve having a design point more appropriate to the flow numbers of the new fuel injector. The GTV remained NASA's sole fuel modulator for ACIC research. To add to the challenge, new research goals were aimed at examining the effectiveness of modulating the pilot flow. The defined operating conditions for the lean-burning combustion platform are shown in Table IV. As can be seen, the GTV would be required to operate at a flow number of 8 (or less) to be the theoretically controlling influence in the flow circuit. This would mean operating the GTV at a near-closed condition. 


\section{The Combustion Rigs}

Within the Candidate Test Article section of this paper a brief description has already been given of the two combustion platforms used by NASA GRC for its ACIC research. The platforms were chosen because of their similarities to actual aircraft engine combustors, their tendency to exhibit combustion instabilities, and because they were available for active combustion controls technology development. The two platforms will now be addressed individually. It is not the intent of this paper to describe these rigs in great detail (the reader will be directed toward specific references for that information). Rather the intent is simply to present the basic construction and to describe the testing configuration in order to provide the context for the experimental test results to be presented in the next section.

\section{Conventional Rich-Burn, Single Nozzle Combustor Rig}

This combustion platform was developed in conjunction with Pratt \& Whitney and UTRC (Ref. 10). It was constructed so as to emulate an instability observed in a real prototype engine, specifically an axial instability having an "unacceptable" magnitude at a frequency of around $525 \mathrm{~Hz}$. Shown schematically in Figure 4, this platform was chosen as the focus for NASA's initial ACIC development. This single-nozzle combustor rig operates at engine pressure and temperature conditions. It operates on liquid jet fuel and uses the same air-blast, 2-stage fuel nozzle and swirler used in the engine. It also employs dilution/cooling and an effusion-cooled liner. A venturi prediffuser and dump diffuser simulate the engine compressor exit (combustor inlet) conditions. A choked nozzle at the combustor exit simulates the engine turbine stator. The nearly choked venturi and choked exit nozzle, in addition to simulating operation inside the engine, provide acoustic isolation from the rest of the facility. These features helped to ensure an accurate simulation of the instabilities in the real prototype engine (at the frequencies that they were actually observed).

During ACIC research tests, the fuel modulation device interfaced with the combustion rig externally. Inside the combustion rig, between the modulator connection point and the fuel injector, an 18 in. length of 1/4 in. inside diameter tubing provided the conduit for transporting modulated fuel. Volume constraints inside the combustor section upstream of the fuel injector coupled with safety issues prevented a closer coupling of the fuel modulator with the fuel injector. As listed in Table III, the flow number of the injector associated with this rig was 110 for the main fuel supply.

Instrumentation used with this rig included fuel dynamic pressure measurements (Pvupstr, Pvdnstr) and four dynamic pressure measurements inside the combustor. These latter sensors, seen in Figure 4, are for collecting information about combustion dynamics.

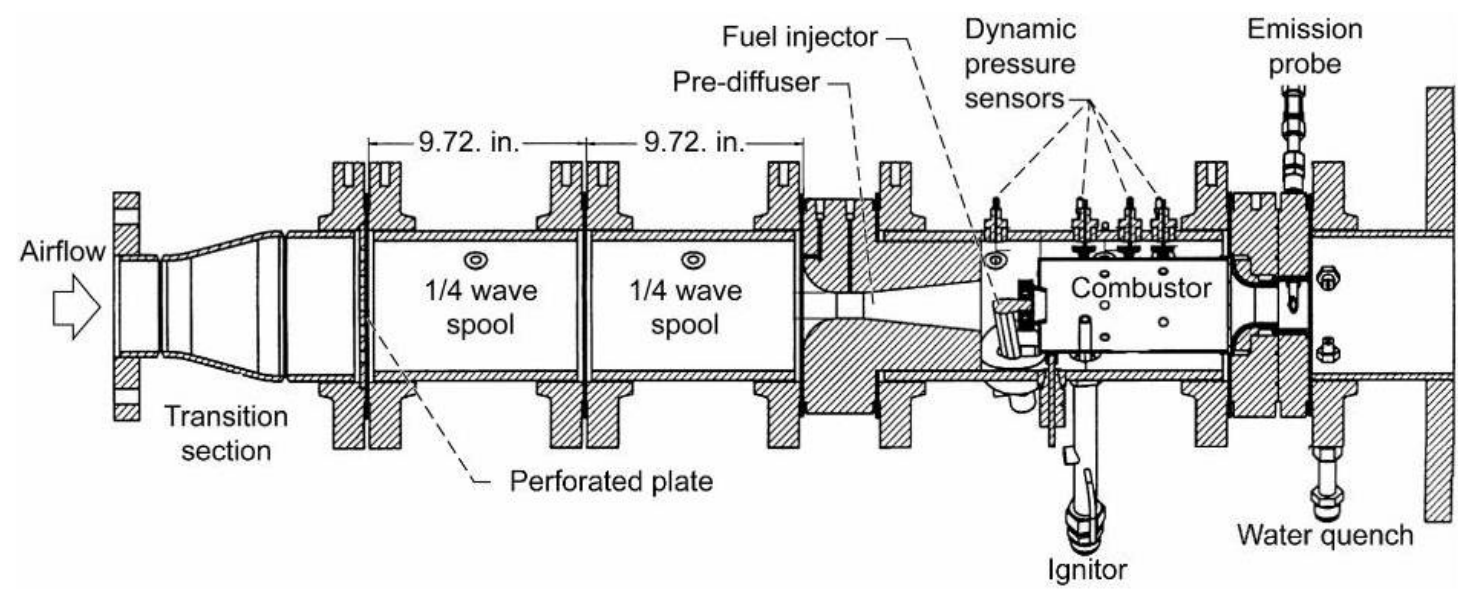

Figure 4.-Rich-burning combustor rig designed to emulate a real prototype engine instability. 


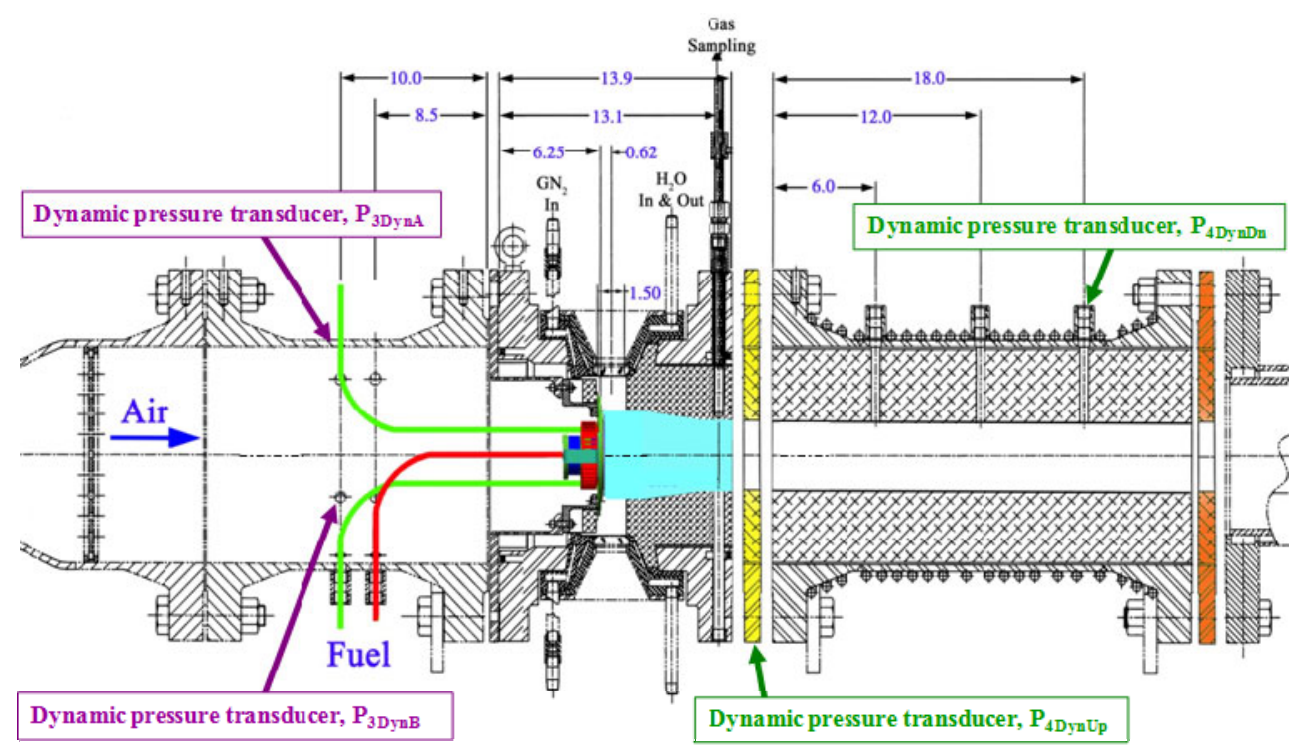

Figure 5.-Advanced lean-burn combustor prototype installed in NASA combustion rig.

\section{Advanced Lean-Burn Low-Emissions Aero-Engine Combustor Prototype}

Several advanced low emissions combustor concepts for aircraft gas turbine engines have been developed in conjunction with NASA's industrial partners. During emissions testing of one of these advanced combustor prototypes, thermoacoustic instability at 500 to $600 \mathrm{~Hz}$ was observed. A drawing of the combustor prototype is shown in Figure 5 and the rig is described more fully in Reference 20. The combustor prototype consists of a pilot and main stage. The pilot operates locally rich and the main stage operates locally lean, however the overall fuel/air ratio is always lean. It was desired to use the pilot to try to influence the combustion instability. As listed in Table IV, the pilot flow number was 8. As with the rich-burn combustor, for the lean-burning combustion platform, the GTV was externally attached. The length of tubing internal to the combustion rig between the fuel modulator connection point and the pilot fuel injector was approximately 26 in.

The combustor was instrumented with dynamic pressure transducers at the locations shown in Figure 5. There were two water cooled dynamic (AC-coupled) pressure transducers upstream of the fuel injector (P3DynA, P3DynB). Downstream of the fuel injector, two uncooled dynamic pressure transducers (P4DynUp, P4DynDn) were each installed in a purged, semi-infinite line configuration in order to isolate the transducers from the hot combustion products. The fuel feed system instrumentation was identical to that with the rich-burn combustor as depicted in Figure 3(b).

\section{Results}

\section{Overview}

The intent of this effort is to show how well the characterized performance of the fuel modulator predicts its measured performance when it is in operation with a combustion rig. In order to accomplish this, it is important to define how performance will be assessed. In the ideal case, the combustor pressure perturbations resulting from the modulation of fuel would be predicted directly. However, the fuel modulation-to-combustor pressure transfer function has no analogy in the non-burning characterization rig (no equivalent to P3b). A good surrogate might be the dynamic mass flow perturbations exiting the fuel injector. While this parameter exists in both the non-burning and burning rigs, it is not directly measured in either situation. So, for this work, the pressure perturbations exiting the modulation valve were chosen as a best-case predictor of performance. As discussed in reference to Figure 3, this parameter 
is measurable for both the characterization rig long configuration (P3a) and for the combustor rigs (Pvdnstr). However, while this parameter should be somewhat proportional to the fuel injector mass flow perturbations, its value as a predictor will be dependent on configuration (e.g., on length and volume of fuel line between the valve and the fuel injector.)

In order to assess the fuel modulator performance by examining valve exit pressure, two sets of analyses are performed. First, the magnitude of the valve exit pressure at steady modulation frequencies is calculated. As discussed earlier, one of the test procedures is to modulate the valve at discrete frequencies from a minimum frequency to a maximum frequency and back, typically in $50 \mathrm{~Hz}$ or $100 \mathrm{~Hz}$ increments. For each modulation frequency, an amplitude spectral plot is generated and the amplitude at the modulation frequency is extracted from the plot. An example of this analysis is shown in Figure 6. Shown on the left is the amplitude spectral plot and on the right the time history data for valve exit pressure (P3B) with a sinusoidal modulation command of $300 \mathrm{~Hz}$ having an amplitude of $4 \mathrm{~V}$ peak-to-peak. The pressure response peak at the modulation frequency that is used for performance assessment is shown in the left spectral plot. This process is repeated for each modulation frequency and the peak pressures compiled into a summary plot. The test results figures in this section contain such summary plots of the amplitude peak response. This provides a straightforward way to compare the valve modulation strength versus frequency.

The second set of analyses consists of using the time history data generated during a sweep-frequency modulation of the valve to construct a transfer function estimate (TFE) which is equivalent to a Bode plot of valve's frequency domain behavior. An example of this analysis is shown in Figure 7. It should be mentioned that in an ideal transfer function the ratio of output to input would be equal to 1 . For these TFE's it should be noted that the ratio of output to input involves physical units of pressure to volts, which have not been normalized, resulting in magnitudes that deviate from what is usually encountered in a typical bode plot. As will be seen in the subsequent discussion, a comparison between the discrete frequency summary plot (essentially a Bode magnitude plot at discrete frequencies) and the TFE gives a feel for how consistently the modulation device is performing. This in turn provides a basis for comparison of the predicted (characterization rig) versus the actual (combustion rig) performance.
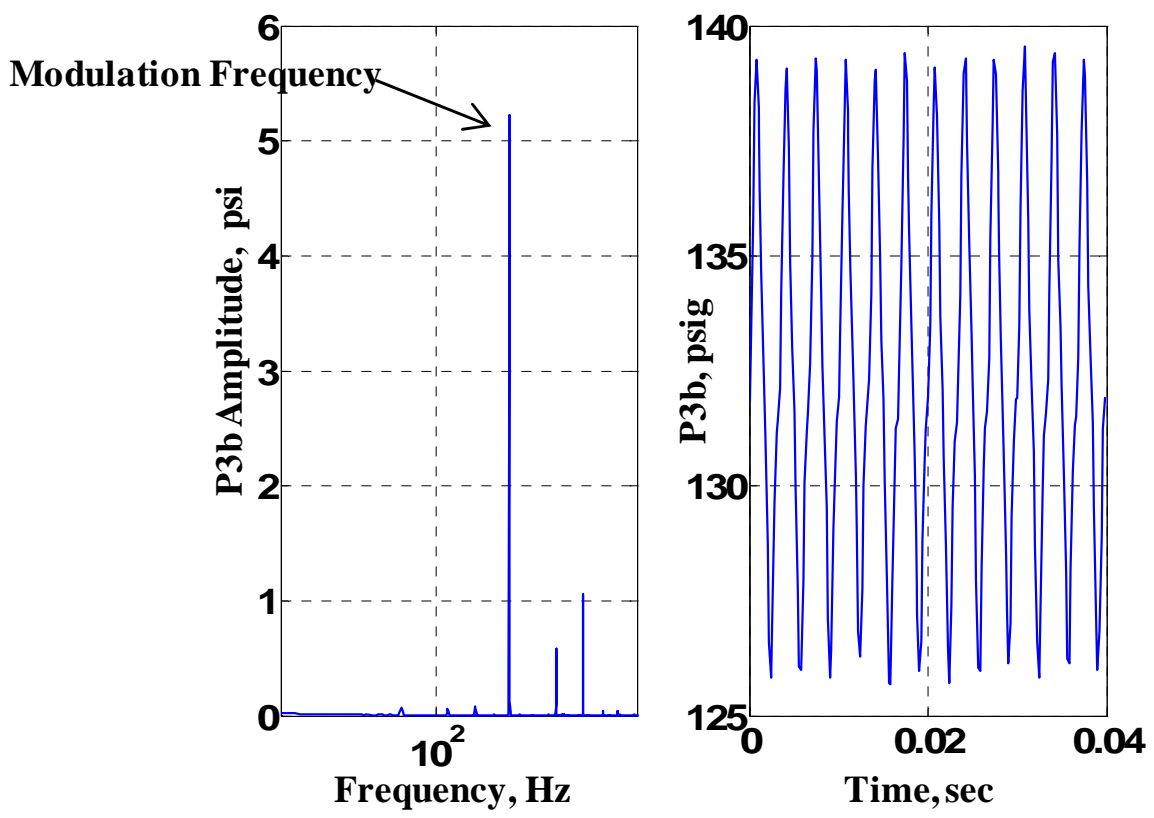

Figure 6.-Example of response to steady-frequency fuel modulation. 

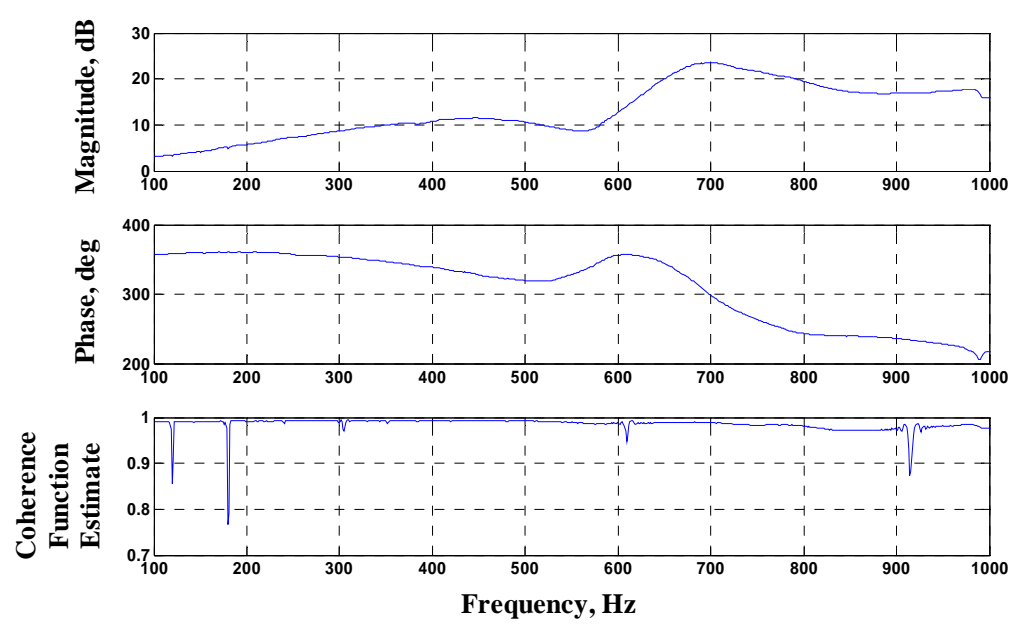

Figure 7.-Example of transfer function estimate generated from frequency sweep data.

\section{Conventional Rich-Burn Single Nozzle Combustor Performance Comparison}

Figures 8, 9, and 10 depict the analyses used to compare the characterized versus actual performance for the fuel modulator operating with the conventional rich-burn combustor rig. Figure 8 shows data for the characterization rig when set up for the short configuration. Figure 9 shows data for the characterization rig in the long configuration. In each of these figures a side-by-side comparison is made between test cases where the amplitude of the modulator input signal was set to a mid-point value (4 $\mathrm{V}$ peak-to-peak) and the maximum allowed ( $8 \mathrm{~V}$ peak-to-peak). For both Figures 8 and 9 the data was collected for a mass flow rate of $375 \mathrm{lbm} / \mathrm{hr}$ with maintained values for $\mathrm{FN}_{\mathrm{m}}$ and $\mathrm{FN}_{\mathrm{i}}$ of 20 (time average) and 100 , respectively.

Figures 8(a) and (c) show summary plots of the response magnitude at each discrete modulation frequency for the two modulation amplitudes. A comparison between the $4 \mathrm{~V}$ peak-to-peak (vpp) data in 8(a) with the 8 vpp data in 8(c) shows that for both sets of data the maximum response is in the neighborhood of 700 to $800 \mathrm{~Hz}$. Further, the amplitude indicates a near-linear change in modulator response given that the response magnitude nearly doubled for the doubling in input amplitude. The transfer function estimates shown in Figures 8(b) and (d) both indicate a fairly flat response over a $1 \mathrm{kHz}$ bandwidth, also showing a maximum response in the neighborhood of 700 to $800 \mathrm{~Hz}$. The consistency in all four plots is an indication of repeatable behavior in the test candidate.

The conventional rich-burning single nozzle combustor has an approximate $18 \mathrm{in}$. length of 1/4 in. stainless steel tubing that extends (internally) from the fuel modulator connection point to the fuel injector. Accounting for this, the characterization rig was configured with a $24 \mathrm{in}$. length of 1/4 in. tube between the modulator's discharge and the simulated fuel injector. The use of a 24 in. versus the use of an 18 in. tube was intended to introduce an added amount of conservatism in the prediction.

The data shown in Figure 9 depicts the fuel modulator performance for this long configuration. In addition to the response summary and TFE plots for P3b shown in Figures 8 and 9 also includes a pair of response summary plots for $\mathrm{P} 3 \mathrm{a}$ (recall from Fig. 3 that P3a is only available in the long configuration). A general examination of the data shows the same good agreement in the shape of the overall magnitude versus frequency response in all six plots. There appears to be a shift in the frequency at which the maximum response is found as compared to the short configuration (Fig. 8), from approximately $750 \mathrm{~Hz}$ to approximately $300 \mathrm{~Hz}$. Comparing Figure 9(a) with Figure 9(d), the same near doubling in response for the doubling of fuel modulator input signal amplitude is observed at the upstream end of the added tubing. This is generally true for the comparison between Figures 9(b) and (e) at the downstream end of the added tubing except for the appearance of an apparent resonance between 600 and $1 \mathrm{kHz}$ in Figure 9(e). An examination of the time history and spectral data showed that this resonance is related to a high frequency resonance above $1200 \mathrm{~Hz}$ that is apparently excited by the harmonic of the modulation 
frequency. This appears to be a phenomenon related to the added tubing length that is excited by the larger amplitude fuel modulations. Interestingly, the amplitude of the fluid pressure modulations at the valve exit for the long configuration are considerably larger than for the short configuration (e.g., comparing Figures 9(d) and 8(c)). This again appears to be a result of the resonance in the added tubing. As suspected, comparing Figures 9(a) and (b) and comparing Figures 9(d) and (e) shows a significant degradation in response magnitude between the upstream end and the downstream end of the added tubing. The degradation appears to be on the order of 90 percent. The TFE's (of P3b) indicate a relatively flat response over a $1 \mathrm{kHz}$ bandwidth with a maximum in the same vicinity $(\sim 300 \mathrm{~Hz})$ as indicated by the amplitude summary charts. Both TFE's show a drop in magnitude and coherence in the neighborhood of $800 \mathrm{~Hz}$, further indicating that the increased response at that frequency seen in Figure 9(e) is not directly attributable to the modulations at that frequency (but rather to the harmonic of those frequencies as stated above).

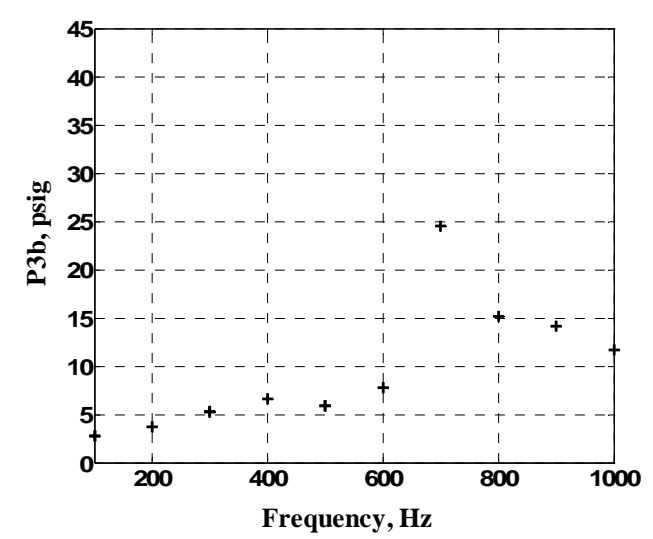

a.) $4 \mathrm{vpp}$

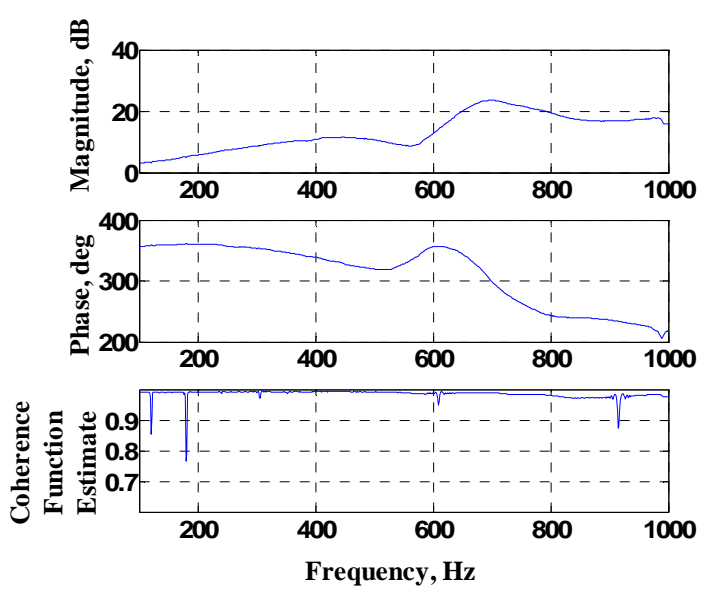

b.) $4 \mathrm{vpp}$

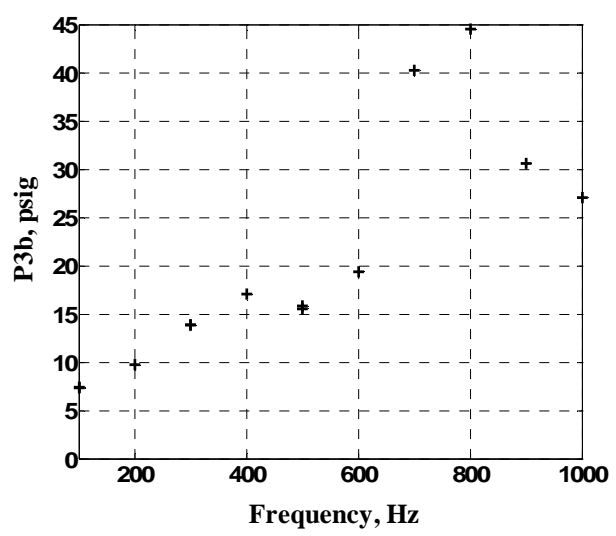

c.) $8 \mathrm{vpp}$
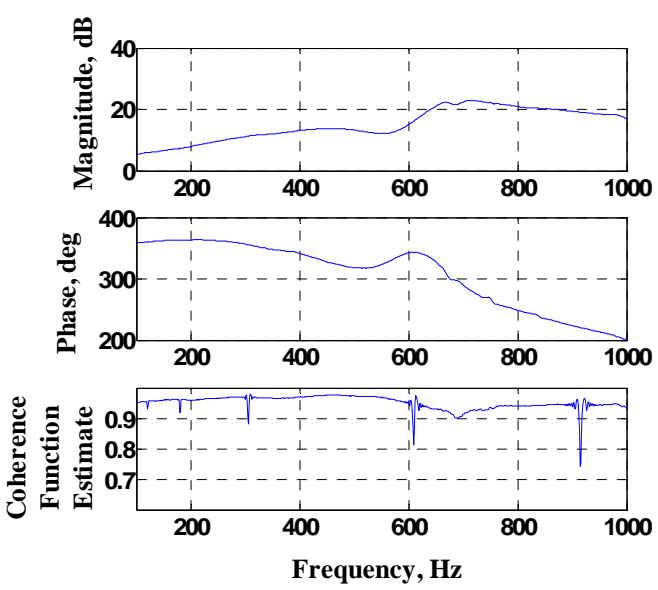

d.) $8 \mathrm{vpp}$

Figure 8.-Characterization rig "short configuration" predicted performance for conventional rich-burn combustor rig. Operating conditions are P4 $200 \mathrm{psig}, \dot{m}_{f}=375 \mathrm{lbm} / \mathrm{hr}, F N_{m}=20, F N_{i}=100$. 


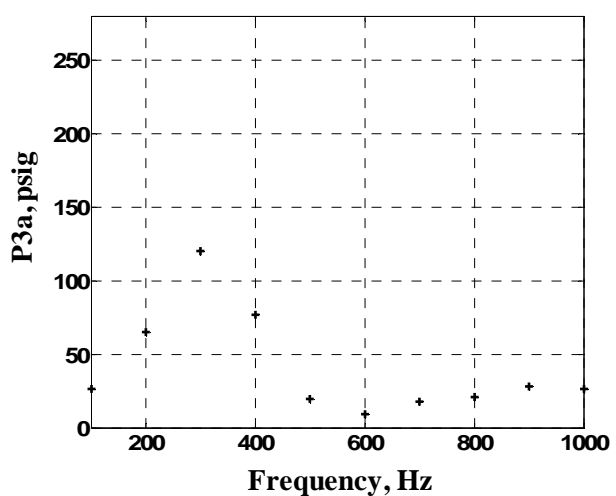

a.) $4 \mathrm{vpp}$

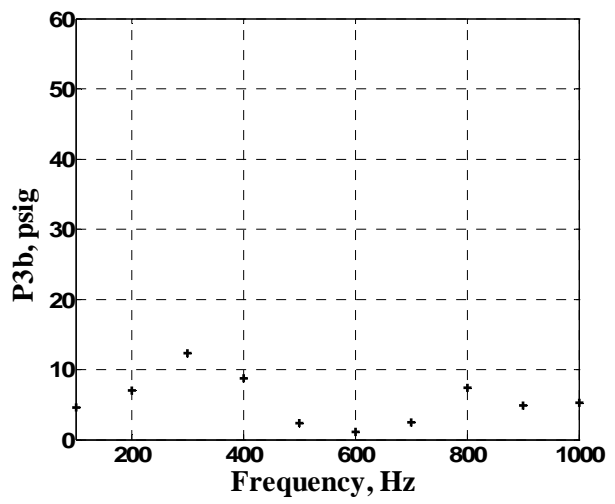

b.) 4 vpp
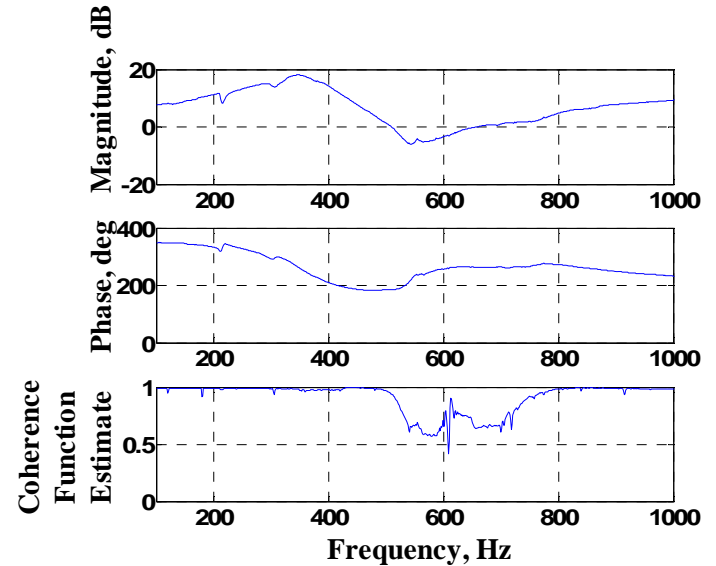

c.) $4 \mathrm{vpp}$

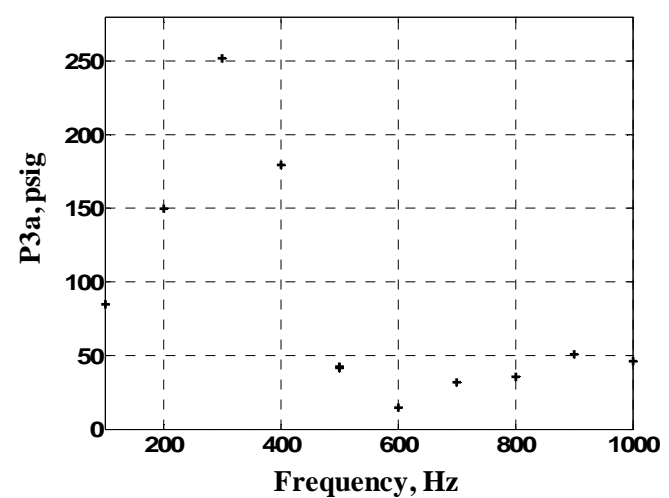

d.) $8 \mathrm{vpp}$

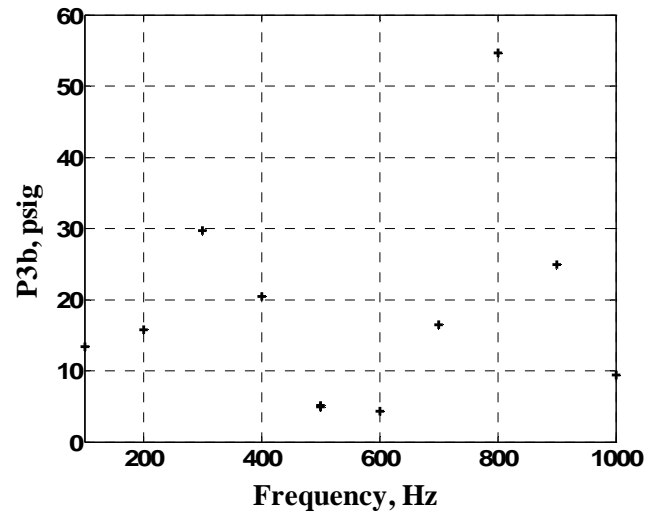

e.) $8 \mathrm{vpp}$

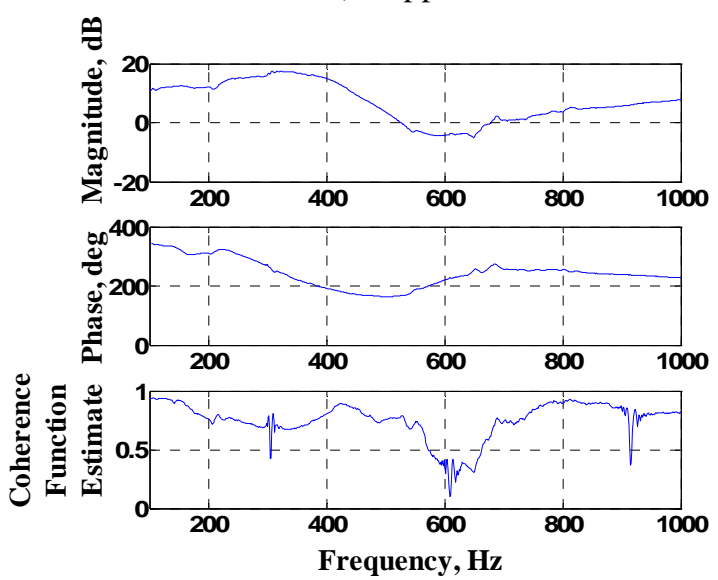

f.) $8 \mathrm{vpp}$

Figure 9.-Characterization rig "long configuration" predicted performance for conventional rich-burn combustor rig. Operating conditions are $P 4=200 \mathrm{psig}, \dot{m}_{f}=375 \mathrm{lbm} / \mathrm{hr}, F N_{m}=20, F N_{i}=100$. 


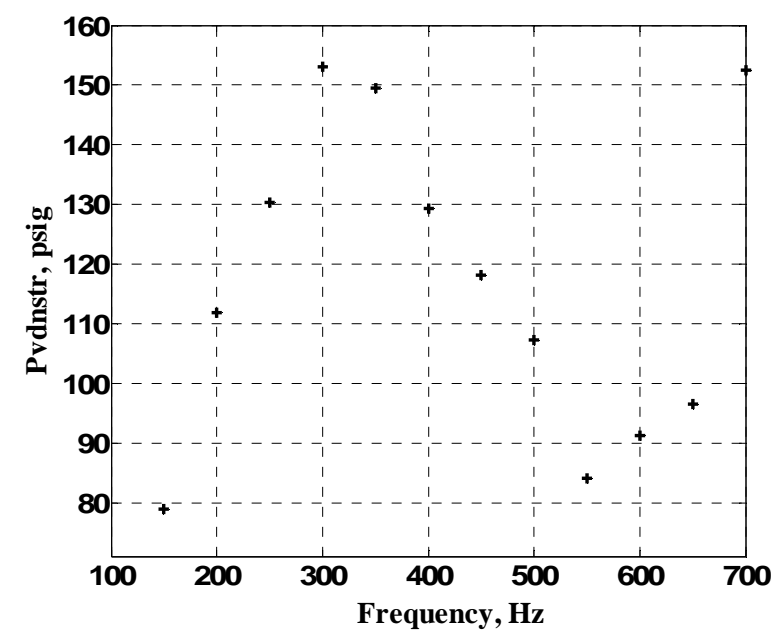

Figure 10.-Conventional rich-burn combustor rig actual performance data. Operating conditions are $P 4=168 \mathrm{psig}, \dot{m}_{f}=300 \mathrm{lbm} / \mathrm{hr}, F N_{m}=24, F N_{i}=100$.

The data in Figure 10 depicts modulator performance during operation with the conventional rich-burn single nozzle combustor rig. The data was collected for an operating condition where the fuel mass flow rate was $300 \mathrm{lbm} / \mathrm{hr}$ and the values for the $\mathrm{FN}_{\mathrm{m}}$ and $\mathrm{FN}_{\mathrm{i}}$ were maintained at 24 and 100, respectively. The single amplitude of the modulator's command signal was $6 \mathrm{vpp}$. Here the measured valve exit pressure is Pvdnstr, which should compare directly to P3a in the characterization rig long configuration since both pressures are at the valve exit and upstream of a length of feed line tubing ahead of the fuel injector. In general, the data in Figures 9(d) and 10 agree on the shape of the response, that is, the comparison shows good agreement on identifying the frequency, $300 \mathrm{~Hz}$, for which the response magnitude is maximum. The amplitude of the response at $300 \mathrm{~Hz}$ for the combustion testing with modulation command of $6 \mathrm{vpp}$ generally agrees with the expected response obtained by interpolating the responses in Figures 9(a) (4 vpp) and 9(d) (8 vpp). Unfortunately, a counterpart to P3b is not available in the combustion rig, so getting an actual measure of modulation strength degradation at the fuel injector entrance is not possible. Using the degradation trend shown by the data in Figure 9, it might be reasonable to expect response magnitudes at the fuel injector input of roughly 10 percent of that at the valve exit.

In summary, the characteristics of the predicted versus the actual performance for the conventional rich-burn combustor are in general agreement. The characterization rig seems to have provided a good prediction of the fuel modulator test candidate's ability to create pressure modulations in the fuel line downstream of the valve and upstream of the fuel injector. Subsequent ACIC testing showed that the test candidate was indeed able to provide good modulation authority into the combustion pressure and was successfully used to actively suppress combustion instability (Ref. 16). However, there are some observable differences in the predicted versus actual response amplitudes. These differences may be due to minor differences in tubing length, in mass flow, or an indication that improvements need to be made to the predictive capability of the rig.

\section{Advance Lean-Burn Low-Emissions Combustor Prototype Performance Comparison}

Figures 11, 12, and 13 depict the analyses used to compare the characterized versus actual performance for the fuel modulator operating with the advanced lean-burn combustor prototype. Figure 11 shows data for the characterization rig when set up for the short configuration. Figure 12 shows data for the characterization rig in the long configuration. In each of these figures a side-by-side comparison is made between test cases where the mass flow rate was $25 \mathrm{lbm} / \mathrm{hr}$ (left) and $75 \mathrm{lbm} / \mathrm{hr}$ (right). Unlike the data shown in the previous section, here the modulator's input signal was held constant 


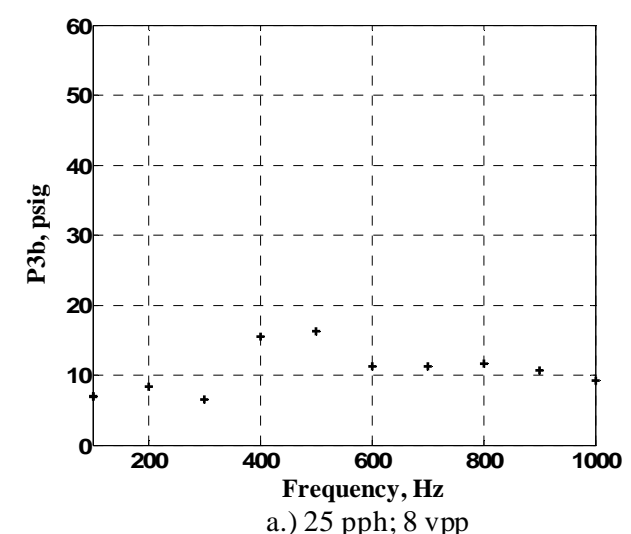

a.) 25 pph; 8 vpp
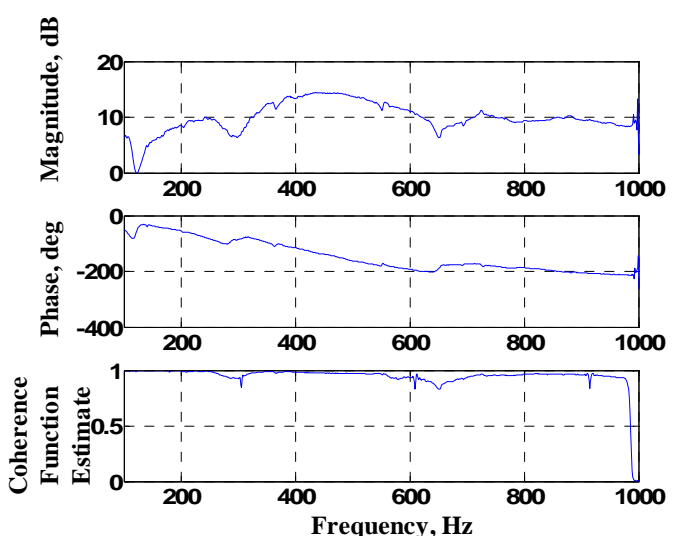

b.) 25 pph; 8 vpp
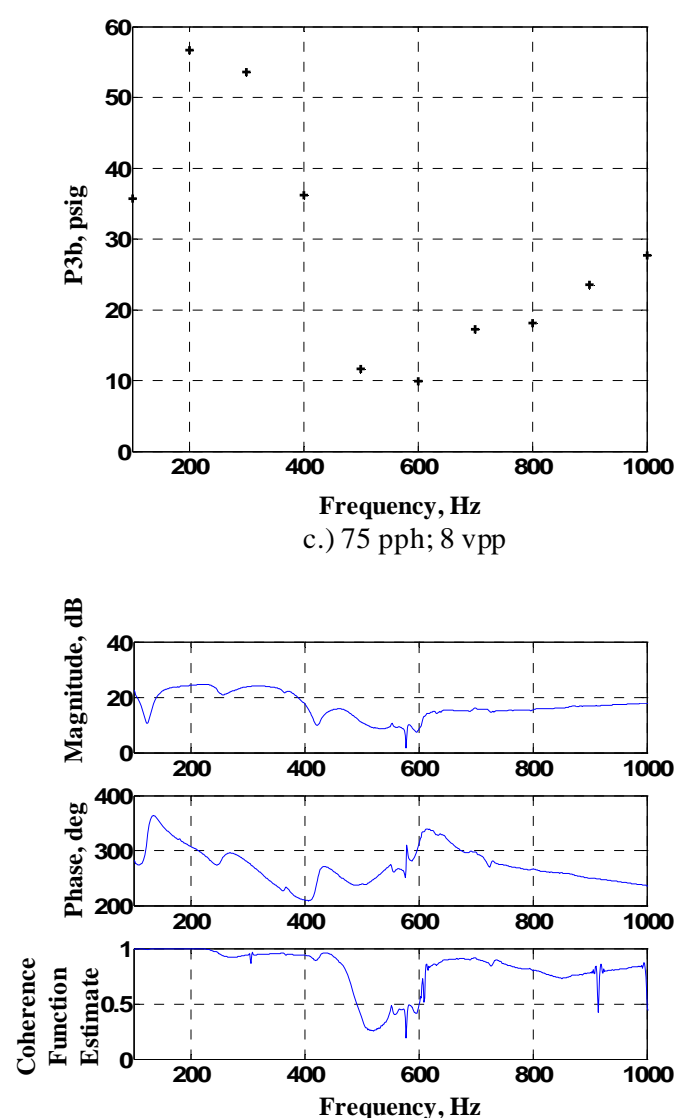

d.) 75 pph; 8 vpp

Figure 11.-Characterization rig "short configuration" predicted performance for the advanced lean-burn combustor prototype. Operating conditions are $P 4=162 p s i g, F N_{m}=10, F N_{i}=8$.

at 8 vpp. Flow numbers for $\mathrm{FN}_{\mathrm{m}}$ and $\mathrm{FN}_{\mathrm{i}}$ were maintained at the value of 10 (time average) and 8 , respectively. As mentioned previously, $\mathrm{FN}_{\mathrm{m}}$ of 10 is very close to fully closed for the GTV, but was felt to be necessary to get good modulation strength.

Examination of Figures 11(a) and (c) shows the maximum response occurring at different frequencies for the two different flows. For the $25 \mathrm{lbm} / \mathrm{hr}$ case, it occurs between 400 and $600 \mathrm{~Hz}$ whereas for the $75 \mathrm{lbm} / \mathrm{hr}$ case it occurs between 100 and $300 \mathrm{~Hz}$. In addition, the peak is considerably lower for the $25 \mathrm{lbm} / \mathrm{hr}$ case. This is believed to be due to the lower pressure drop across the valve at the lower flow providing less ability to modulate the fluid pressure at the valve exit. The TFE's shown in Figures 11(b) and (d) show a relatively flat frequency response with an increase in amplitude in roughly the same frequency range as the steady modulation summary plots in Figures 11(a) and (c). The coherence plot in Figure 11(d) shows a drop in coherence in the vicinity of 500 to $600 \mathrm{~Hz}$. Examining the time history and spectral data showed sensitivity to exciting the harmonic of the modulation frequency such that the energy appears distributed between the fundamental and the harmonic. This seems to be an example, even in the short configuration, of the feed lines interacting with the valve to impact the amount of modulation strength available. These results seem to indicate a relatively modest ability to modulate fluid pressure even in the short configuration.

The advanced lean-burn combustor prototype had a 26 in. length of 1/4 in. tube that extended (internally) from the fuel modulator connection point to the fuel injector. Considering the apparent poor performance shown for the short configuration, only a $12 \mathrm{in.} \mathrm{length} \mathrm{of} \mathrm{1/4} \mathrm{in.} \mathrm{tube} \mathrm{was} \mathrm{installed} \mathrm{in} \mathrm{the}$ characterization rig to establish the long configuration. The performance results for this configuration are 


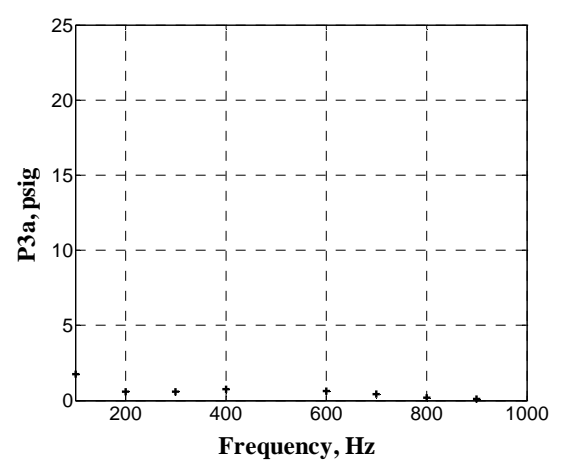

a.) $25 \mathrm{pph} ; 8 \mathrm{vpp}$

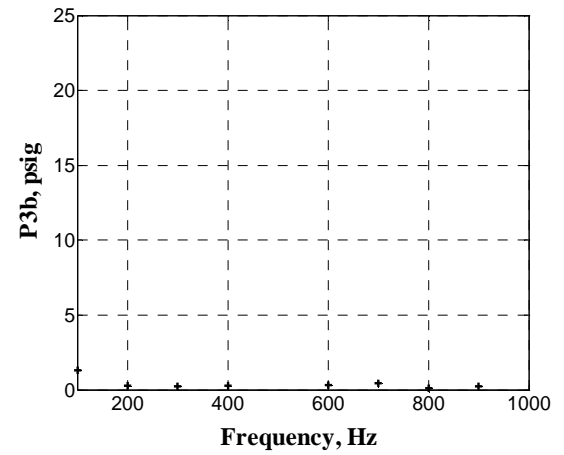

b.) $25 \mathrm{pph} ; 8 \mathrm{vpp}$
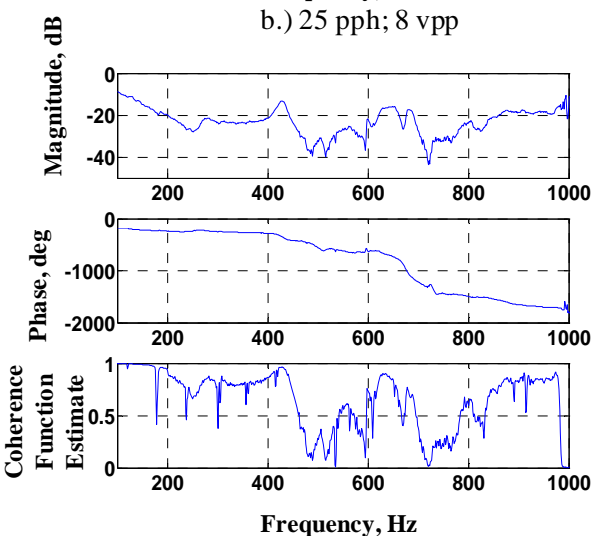

c.) $25 \mathrm{pph} ; 8 \mathrm{vpp}$

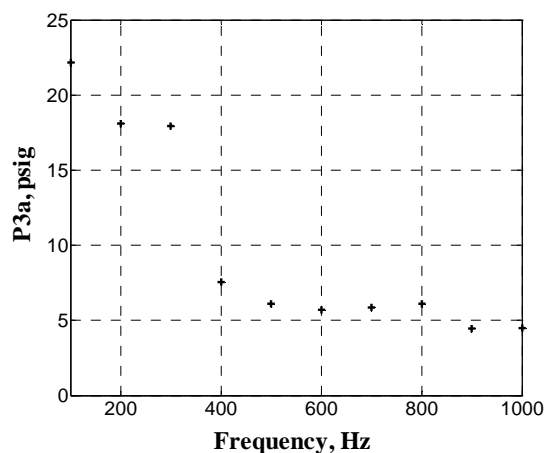

d.) $75 \mathrm{pph} ; 8 \mathrm{vpp}$

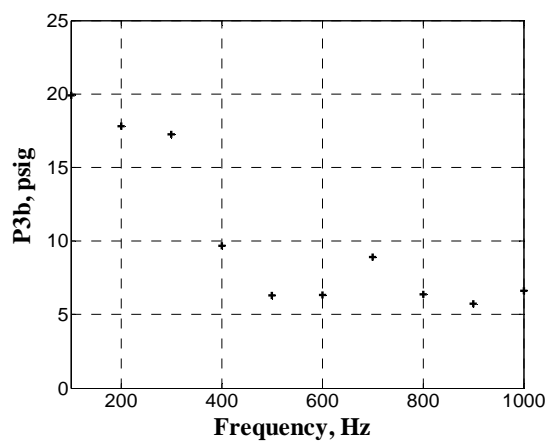

e.) $75 \mathrm{pph} ; 8 \mathrm{vpp}$
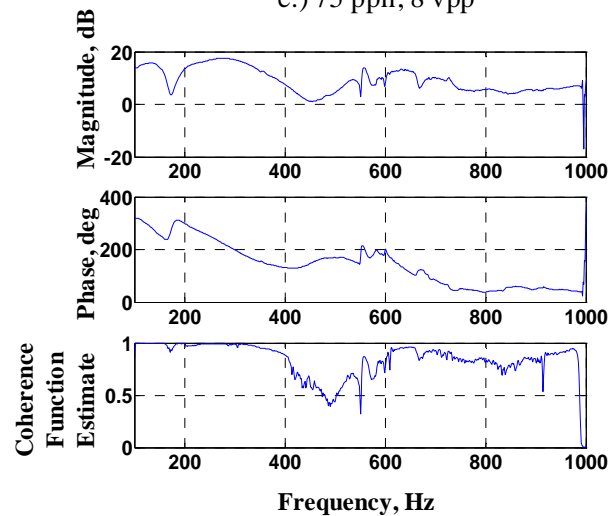

f.) $75 \mathrm{pph} ; 8 \mathrm{vpp}$

Figure 12.-Characterization rig "long configuration" predicted performance for the advanced lean-burn combustor prototype. Operating conditions are $P 4=162$ psig, $F N_{m}=10, F N_{i}=8$.

depicted in Figure 12. Comparing Figure 11(a) to Figures 12(a) and (b) shows that, for the low flow case, there is a substantial drop in the valve exit pressure modulation at the upstream end of the added tube (Fig. 12(a)), compared to the short configuration (Fig. 11(a)), and a reduction to essentially no response at the fuel injector inlet at the downstream end of the tube (Fig. 12(b)). With the responses being so small, it is difficult to conclude that there is any kind of peak frequency associated with this condition. The TFE for this condition shown in Figure 12(c) seems to bear this out. No apparent peak is seen in the magnitude plot, and the coherence plot indicates very poor correlation between the modulation command and the fuel injector inlet pressure.

Comparing Figure 11(c) to Figure 12(d) shows that, for the higher flow case, there is about a 60 to 70 percent reduction in the valve exit pressure modulation strength compared to the short configuration. The maximum amplitude frequency for the long configuration is also in the neighborhood of $300 \mathrm{~Hz}$. Comparing Figures 12(d) and (e) shows minimal degradation in amplitude between the upstream end of 

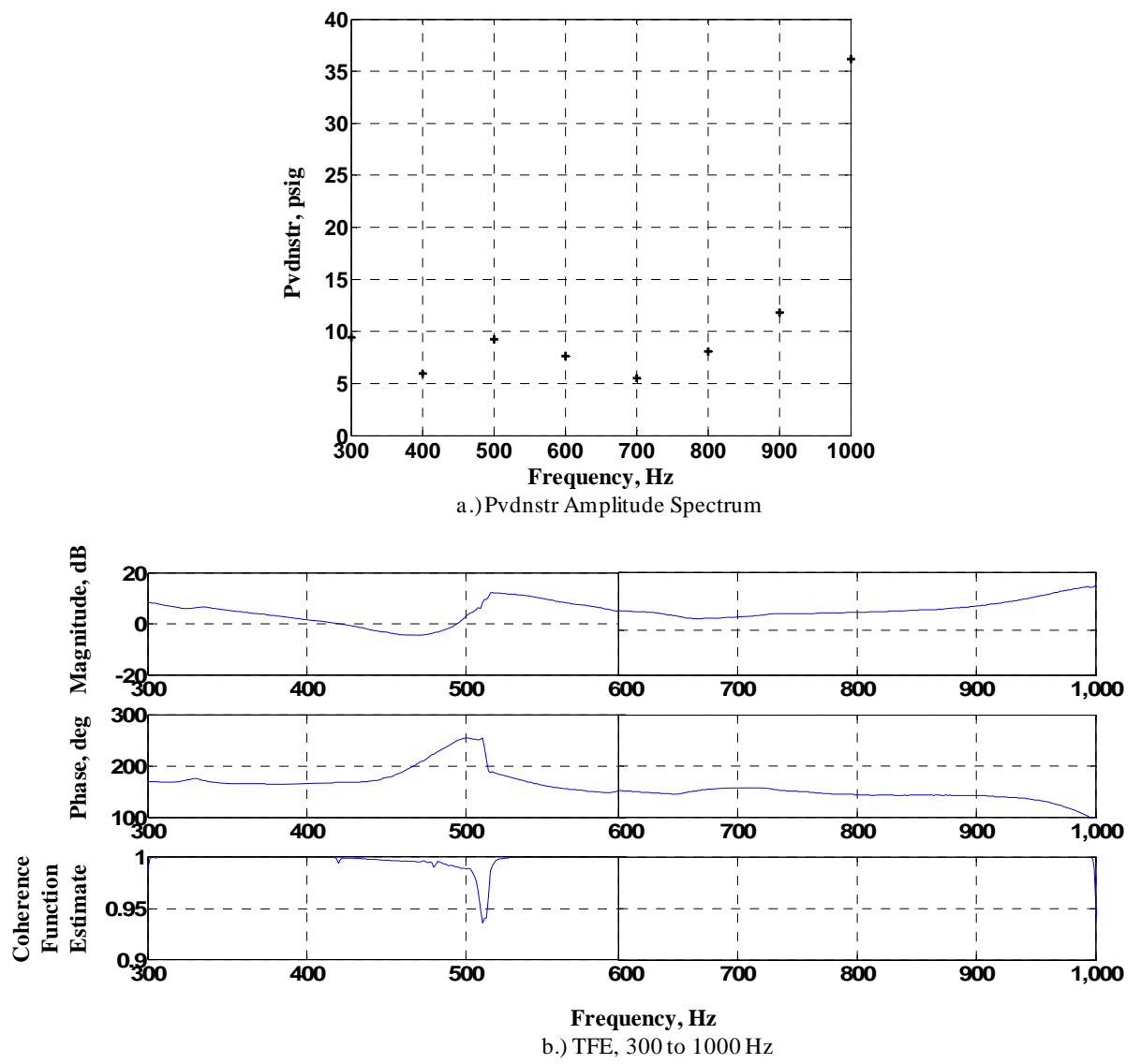

Figure 13.-Advanced lean-burn combustor prototype actual performance data. Operating conditions are $P 4=162 \mathrm{psig}, \dot{m}_{f}=60 \mathrm{lbm} / \mathrm{hr}, F N_{m}=13, F N_{i}=8$.

the added tube and the downstream end. The TFE for the $75 \mathrm{lbm} / \mathrm{hr}$ condition in Figure 12(f) shows a relatively flat frequency response with a maximum in the neighborhood of $300 \mathrm{~Hz}$. This agrees with the discrete frequency summary in Figure 12(e). The coherence plot once again indicates poor correlation between the modulation command and the fuel injector inlet pressure in the range are of 500 to $600 \mathrm{~Hz}$, and the time history and spectral data again shows a harmonic response in that frequency region. Since this harmonic response was observed in several cases, it was thought that it may be a mechanical resonance in the valve. However, examining the data from the mechanical displacement sensor in the valve shows no similar harmonic response. It was thus concluded that there may be a configurationindependent fluidic resonance that is part of the valve's construction. This was not investigated further.

Figure 13 shows performance data for the fuel modulator when it was in operation with the advanced lean-burning combustor prototype. The conditions under which the combustor was operating included a single mass flow rate of $60 \mathrm{lbm} / \mathrm{hr}$ and settings for $\mathrm{FN}_{\mathrm{m}}$ and $\mathrm{FN}_{\mathrm{i}}$ of 13 (time averaged) and 8, respectively. The modulator flow number was chosen based on operational experience with the combustor that showed slightly better response with $\mathrm{FN}_{\mathrm{m}}$ at 13 rather than at 10 as was used in the characterization rig. The maximum amplitude summary chart, Figure 13(a), does not show a peak in the response at around $300 \mathrm{~Hz}$ as was seen in the characterization rig. Rather, the peak is seen at around $1000 \mathrm{~Hz}$. The sweep frequency data was collected in two separate sweeps: one from 300 to $700 \mathrm{~Hz}$ and a second from 600 to $1000 \mathrm{~Hz}$. The TFE data, Figure 13(b), also indicates a peak response at around $1000 \mathrm{~Hz}$, in agreement with the maximum amplitude data in Figure 13(a), but in disagreement with the characterization rig data. 
In summary, the characteristics of the predicted versus the actual performance for the advanced leanburn combustor prototype agree only in a somewhat qualitative sense. The characterization rig predicted poor, inconsistent performance and this was in fact observed in the combustor rig as well. This was ultimately borne out in subsequent ACIC testing that showed that the test candidate was not able to provide good modulation authority into the combustion pressure, and thus was not able to be used for active instability suppression using pilot flow modulation (Ref. 21). It is difficult, however, to label what was observed as "good" agreement. Since the characterization rig data seems to have provided different results concerning, for instance, the frequency at which the maximum amplitude pressure perturbations occur, it may be that the characterization rig was a poor predictor of performance. On the other hand, since the amplitudes were small, it may be that the results are consistent but with large errors. Further, some performance differences may be attributable to the differences in the tubing lengths and mass flow between the characterization rig and the combustor rig. It can likely be concluded that: a) this test candidate was a poor performer for these conditions, probably because it was being operated severely offdesign; and b) a better valve operated under more consistently comparable conditions may provide improved prediction results. As will be discussed in the next section, the latter conclusion will continue to be a targeted area of research in NASA's ACIC effort.

\section{Lessons Learned and Future Work}

ACIC research is ongoing at NASA GRC. The research began with an initial focus of ACIC proof-ofconcept through modulation of a rich-burn combustor's main fuel supply. That focus has now shifted to the modulation of the pilot flow in lean-burn, low-emissions combustors. Extrapolating into the future, modulation of even smaller flows (i.e., the flow associated with individual injectors of an injection array) are a likely requirement. Given this trend toward the modulation of smaller flows, it becomes even more critical to have an accurate means of predicting performance from potential modulation candidates so that the candidate having the best chance of success is selected. To this end, NASA's fuel modulator evaluation program has identified areas of improvement. These areas include:

1. Candidate Modulators-To increase the likelihood of successful modulation of small flows, multiple new candidate concepts are in development and will become available for evaluation in the near future. These candidates are being designed for flow numbers in the range of 3 to 8 .

2. Candidate Evaluation Rigor-Testing will be more strictly conducted at conditions tied to the eventual combustor use and the characterization testing will include design and off-design conditions to better determine the limits of a candidate's performance.

3. Modeling-Mathematical models in development are able to describe the modulator interfaced with a fluidic system and can provide insight into additional conditions that should be included in the test matrix.

4. Using Fuel as Working Fluid-For ease of operation, city water has been the characterization rig's working fluid to date. It is unknown if this biases performance predictions. Efforts are underway to identify a facility at NASA GRC where fuel could be safely used in a non-combusting environment.

5. Inference Studies-The characterization rig's non-burning environment does not allow the prediction of combustion-influenced behavior (e.g., the actual pressure amplitude perturbations resulting from fuel modulations). However, fuel modulation into a combustor may provide useful transfer-functionlike information. Others have attempted to develop methods for correlating modulator pressure and the magnitude of the combustor pressure response at the frequencies of the modulation (Ref. 22). Similar efforts would be of particular interest if the modulation was being conducted for instability control. It might then be possible to infer the minimum amplitude required for influencing the instability. 


\section{Conclusions}

A characterization rig, that was designed and developed at NASA Glenn to evaluate high bandwidth fuel modulators for suitability in active combustion control research, was used to obtain predicted performance data for a specific fuel modulation valve. The fuel modulator, a magnetostrictive-actuated proportional valve designed and developed by The Georgia Institute of Technology, was evaluated for use as a modulator of the main fuel supply for a conventional rich-burn combustor platform. The flow number of the combustor's main fuel supply was appropriate to the design point of the modulator and permitted the modulator to operate as a controlling influence in the fluid circuit. The results of the characterization studies predicted good overall response magnitude and they predicted the frequency of maximum response. These predictions matched well with measurement data collected during the time the modulator operated in the combustion platform environment. The same candidate test article was later evaluated for use as a modulator of the pilot fuel supply for an advanced lean-burn combustor prototype. The flow number of the combustor's pilot flow represented a drastic departure from the modulator's design point and caused operation of the modulator at a near-closed condition. The results of the characterization studies showed that the modulator had very poor authority for acting as the controlling influence in the fluid circuit. It predicted a low overall response magnitude and inconsistent frequency of maximum influence. The measurement data collected during the time the modulator operated with the lean-burning combustor further reinforced this conclusion of poor authority, and also brought to light potential improvements in how to investigate modulators for these types of combustors. Future work will include additional development of fuel modulators more appropriately sized for pilot flows and improvements to how characterization tests of these devices are performed.

\section{References}

1. Lefebvre, A.H., Gas Turbine Combustion, 2nd edition, Taylor \& Francis, 1999.

2. Schadow, K., Yang, V., Culick, F., Rosfjord, T., Sturgess, G., and Zinn, B., “Active Combustion Control for Propulsion Systems,” AGARD Report 820, September 1997.

3. Zinn, B.T., and Neumeier, Y., “An Overview of Active Control of Combustion Instabilities,” AIAA-97-0461, January 1997.

4. Annaswamy, A.M., Ghoneim, A.F., "Active Control of Combustion Instability: Theory and Practice,” in IEEE Control Systems Magazine, vol. 22, no. 6, pp. 37-54, December 2002.

5. Murugappan, S., Aharya, S., Gutmark, E., and Messina, T., "Characteristics and Control of Combustion Instabilities in a Swirl-Stabilized Spray Combustor,” 35th Joint Propulsion Conference and Exhibit, Los Angeles, CA. AIAA-99-31259, June 1999.

6. McManus, K.R., Magill, J.C., Miller, M.F., and Allen, M.G., “Closed-Loop System for Stability Control in Gas Turbine Combustors,” AIAA-97-0463, January 1997.

7. Johnson, C., Neumeier, Y., Neumaier, M., Zinn, B., Darling, D., and Sattinger, S., "Demonstration of Active Control of Combustion Instabilities on a Full-Scale Gas Turbine Combustor,” ASME Turbo Expo 2001, New Orleans, LA. ASME Paper 2001-GT-0519, June 2001.

8. Hibshman, J.R., Cohen, J.M., Banaszuk, A., Anderson, T.J., and Alholm, H.A., “Active Control of Combustion Instability in a Liquid-Fueled Sector Combustor,” International Gas Turbine \& Aeroengine Congress and Exhibition, ASME Paper 99-GT-215, June 1999.

9. Kiel, B., "Review of Advances in Combustion Control, Actuation, Sensing, Modeling and Related Technologies for Air Breathing Gas Turbines,” 39th Aerospace Sciences Meeting and Exhibit, Reno NV, AIAA-2001-0481, January 2001.

10. Cohen, J.M., et al, "Experimental Replication of an Aeroengine Combustion Instability," International Gas Turbine \& Aeroengine Congress \& Exhibition, Munich, Germany, ASME Paper 2000-GT-0093, May 2000. 
11. DeLaat, J.C., Breisacher, K.J., Saus, J.R., and Paxson, D.E., “Active Combustion Control for Aircraft Gas Turbine Engines,” 36th Joint Propulsion Conference and Exhibition, Huntsville, AL, AIAA-2000-3500, NASA/TM-2000-210346, July 2000.

12. Kopasakis, G., and DeLaat, J., "Adaptive Instability Suppression Controls in a Liquid-Fueled Combustor," $38^{\text {th }}$ Joint Propulsion Conference and Exhibit, Indianapolis, IN, AIAA-2002-4075, NASA/TM-2002-21805, July 2002.

13. Nguyen, Q., "Measurements of Equivalence Ratio Fluctuations in a Lean Premixed Prevaporized (LPP) Combustor and its Correlation to Combustion Instability,” ASME Turbo Expo, Amsterdam, The Netherlands, ASME paper GT-2002-30060, June 2002.

14. Barooah, P., Anderson, T.J., and Cohen, J.M., “Active Combustion Instability Control with Spinning Valve Actuator,” ASME Turbo Expo 2002, Amsterdam, The Netherlands. ASME Paper GT-200230042, June 2002.

15. Cannon, S., Smith, C., and Lovett, J., "LES Modeling of Combustion Dynamics in a Liquid-Fueled Flametube Combustor,” 36th Joint Propulsion Conference and Exhibit, AIAA-2000-3126, July 2000.

16. Kopasakis, George, DeLaat, John C., and Chang, Clarence T., "An Adaptive Instability Suppression Controls Method for Aircraft Gas Turbine Engine Combustors,” Journal of Propulsion and Power, vol. 25, no. 3, pp. 618-627, 2009; NASA TM: 2008-215202.

17. Le, D., DeLaat, J., and Chang, C., "Control of Thermo-Acoustic Instabilities: The Multi-Scale Extended Kalman Approach,” $39^{\text {th }}$ Joint Propulsion Conference and Exhibit, Huntsville, AL, AIAA-2003-4934, July 2003.

18. Saus, Joseph R., Chang, Clarence T., DeLaat, John C., and Vrnak, Daniel R., "Design and Implementation of a Characterization Test Rig for Evaluating High Bandwidth Liquid Fuel Flow Modulators," $45^{\text {th }}$ Joint Propulsion Conference and Exhibit, Denver, CO, AIAA-2009-4886, August 2009, NASA/TM-2010-216105, April 2010.

19. Neumeier, Y., Lubarsky, R., Heising, R., Israeli, O., Neumaeir, M., and Zinn, B.T., "Liquid Injector Actuator for Control of Combustion Processes," $34^{\text {th }}$ AIAA/ASME/SAE/ASEE Joint Propulsion Conference and Exhibit, Cleveland, OH, AIAA-98-3540, July 1998.

20. DeLaat, J.C., and Paxson, D.E., "Characterization and Simulation of the Thermoacoustic Instability Behavior of an Advanced, Low Emissions Combustor Prototype," 44th Joint Propulsion Conference and Exhibit, Hartford, Connecticut, July 21-23, 2008, AIAA-2008-4878, NASA/TM-2008215291.

21. DeLaat, J.C., Kopasakis, G., Saus, J.R., Chang, C.T., and Wey, C., “Active Combustion Control for Aircraft Gas-Turbine Engines-Experimental Results for an Advanced, Low-Emissions Combustor Prototype,” 50th AIAA Aerospace Sciences Meeting, Nashville, TN, January 2012 (submitted for publication).

22. Yi, T., and Santavicca, D.A., "Forced Flame Response of Turbulent Liquid-Fueled Lean-DirectInjection Combustion to Fuel Modulations,” Journal of Propulsion and Power, AIAA, vol. 25, no. 6, November-December 2009, pp. 1259-1271. 



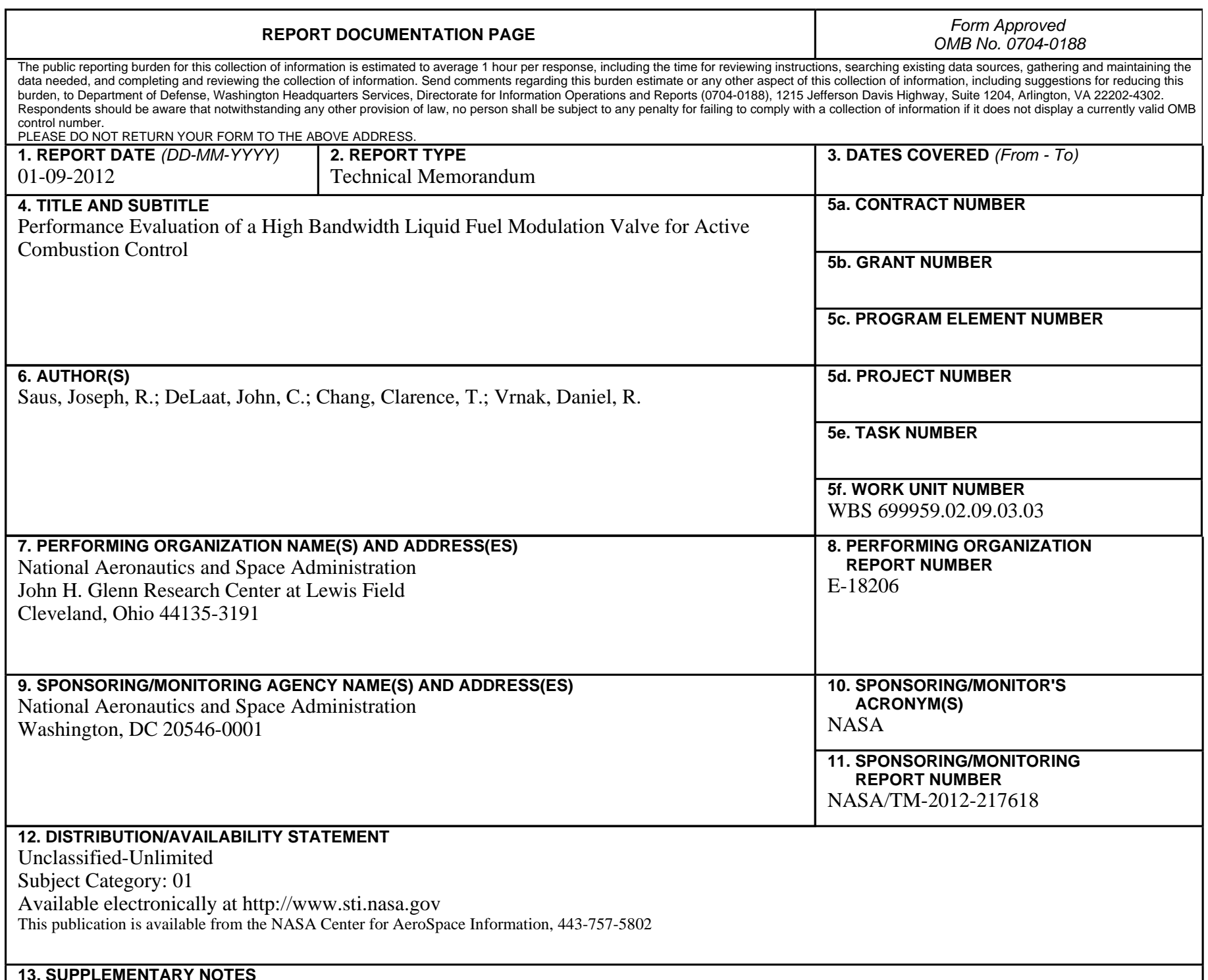

\section{SUPPLEMENTARY NOTES}

\section{ABSTRACT}

At the NASA Glenn Research Center, a characterization rig was designed and constructed for the purpose of evaluating high bandwidth liquid fuel modulation devices to determine their suitability for active combustion control research. Incorporated into the rig's design are features that approximate conditions similar to those that would be encountered by a candidate device if it were installed on an actual combustion research rig. The characterized dynamic performance measures obtained through testing in the rig are planned to be accurate indicators of expected performance in an actual combustion testing environment. To evaluate how well the characterization rig predicts fuel modulator dynamic performance, characterization rig data was compared with performance data for a fuel modulator candidate when the candidate was in operation during combustion testing. Specifically, the nominal and off-nominal performance data for a magnetostrictiveactuated proportional fuel modulation valve is described. Valve performance data were collected with the characterization rig configured to emulate two different combustion rig fuel feed systems. Fuel mass flows and pressures, fuel feed line lengths, and fuel injector orifice size was approximated in the characterization rig. Valve performance data were also collected with the valve modulating the fuel into the two combustor rigs. Comparison of the predicted and actual valve performance data show that when the valve is operated near its design condition the characterization rig can appropriately predict the installed performance of the valve. Improvements to the characterization rig and accompanying modeling activities are underway to more accurately predict performance, especially for the devices under development to modulate fuel into the much smaller fuel injectors anticipated in future lean-burning low-emissions aircraft engine combustors.

15. SUBJECT TERMS

Active combustion control; High bandwidth liquid fuel actuation

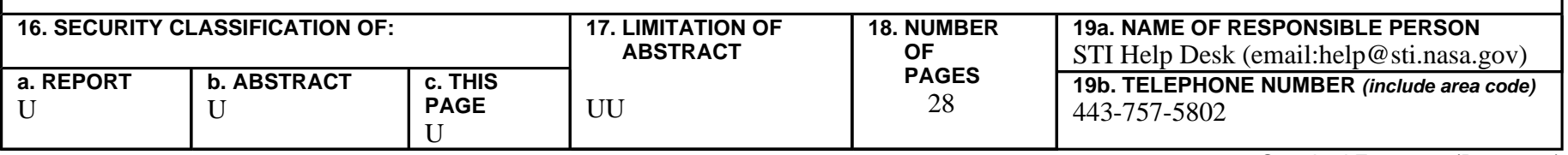



